\title{
Oculomotor consequences of abrupt object onsets and offsets: Onsets dominate oculomotor capture
}

\author{
WALTER R. BOOT and ARTHUR F. KRAMER \\ University of Illinois at Urbana-Champaign, Urbana, Illinois \\ and \\ MATTHEW S. PETERSON \\ George Mason University, Fairfax, Virginia
}

\begin{abstract}
Previous research has shown that the appearance of an object (onset) and the disappearance of an object (offset) have the ability to influence the allocation of covert attention. To determine whether both onsets and offsets have the ability to influence eye movements, a series of experiments was conducted in which participants had to make goal-directed eye movements to a color singleton target in the presence of an irrelevant onset/offset. In accord with previous research, onsets had the ability to capture the eyes. The offset of an object demonstrated little or no ability to interrupt goal-directed eye movements to the target. Two experiments in which the effects of onsets and offsets on covert attention were examined suggest that offsets do not capture the eyes, because they have a lesser ability to capture covert attention than do onsets. A number of other studies that have shown strong effects of offsets on attention have used offsets that were uncorrelated with target position (i.e., nonpredictive), whereas we used onsets and offsets that never served as targets (i.e., antipredictive). The present results are consistent with a new-object theory of attentional capture in which onsets receive attentional priority over other types of changes in the visual environment.
\end{abstract}

It is generally assumed that attention can be guided in two distinct ways during visual search (Klein \& Shore, 2000). Endogenous, or goal-directed, shifts of attention occur volitionally and are directed toward likely target locations. Exogenous, or stimulus-driven, shifts of attention occur regardless of intention, even when the stimulus feature driving attention is antipredictive (never associated with the target location) or uncorrelated with the target of search. The human visual system must balance the need to selectively attend to goal-relevant information against the need for immediate interruption by sudden changes in the visual environment. In other words, exogenous and endogenous forces must interact fluidly to allow attention to be correctly allocated depending on the situation. If goal-directed attention were uninterruptible, we would often miss important changes in the visual environment. On the other hand, if every change in the environment captured attention, goal-directed action would be virtually impossible. Successful visual search (and survival) depends on an attention system that correctly weighs the value of goal-directed and stimulus-driven activation (Rauschenberger \& Yantis, 2001; Theeuwes, 1991; Yantis \& Jonides, 1990).

Correspondence concerning this article should be addressed to A. F. Kramer, Beckman Institute, University of Illinois at Urbana-Champaign, 405 N. Mathews, Urbana, IL 61801 (e-mail: akramer@s.psych.uiuc.edu).
The visual system must achieve some kind of balance between these two often opposing forces competing for control of attention. Research on attentional and oculomotor capture addresses this balance. The attentional capture literature indicates that certain abrupt changes in the environment (such as the sudden appearance or disappearance of an object) capture attention, even when these changes are irrelevant to the task one is performing. In addition to controlling covert attention, the sudden appearance of an object can capture the eyes (see Theeuwes \& Godijn, 2001, for review of attentional and oculomotor capture). Two types of changes that can occur in the visual environment that have been studied are the appearance (onset) of an object and, to a lesser extent, the disappearance (offset) of an object, and a brief review of the attentional consequences of these two types of transients is provided below.

\section{Onset/Offset Transients and Attention}

There is substantial evidence suggesting that an abrupt object onset (the appearance of a new object) is especially effective in capturing attention (e.g., Enns, Austen, Di Lollo, Rauschenberger, \& Yantis, 2001; Jonides \& Yantis, 1988; Müller \& Rabbitt, 1989; Yantis \& Jonides, 1984, 1990). For example, Yantis and Jonides (1984) found that when the target letter in a visual search task appeared as an onset, reaction time (RT) did not suffer as the number of distractors increased. The onset in the search display was 
associated with the target letter with chance probability and, therefore, would not be expected to be initially attended more often than any other stimulus. However, flat search slopes when the target appeared as an onset were consistent with attention's being first directed to the onset item, followed by a serial search of nononset items. Yantis and Jonides (1984) interpreted these results as evidence for the ability of onsets to capture attention. Even though there was no advantage in attending to the onset, attentional priority was given to the onset item. It should be noted that it is not the uniqueness of the onset item that attracts attention. In a similar experiment, Jonides and Yantis (1988) found that time to find a target randomly associated with a unique color or luminance increased with the number of distractors in the display. Thus, it is not the case that any salient property will receive attentional priority. The perceptual system seems to be especially sensitive to the appearance of new objects.

Although many studies suggest that object onsets capture attention, fewer studies have focused on object offsets. Offset transients have been shown indirectly to influence attention by modulating the ability of onsets to capture attention. When multiple offset transients occur simultaneously with an abrupt object onset, the power of an onset to capture attention is decreased (Martin-Emerson \& Kramer, 1997; Miller, 1989). In a display modeled after the visual search task developed by Yantis and Jonides (Jonides \& Yantis, 1988; Yantis \& Jonides, 1984), Martin-Emerson and Kramer found that increasing the number of line segments removed to reveal the search stimuli (partial offsets) decreased attentional capture by onsets. Although this is not direct evidence for the ability of offset transients to attract attention, it does point to the fact that offsets have attentional consequences. MartinEmerson and Kramer interpreted their findings as supporting an interrupt threshold hypothesis, in which attention is directed by overall display change, rather than by the unique ability of onsets to capture attention.

Several other studies also have provided evidence that onsets are not special in their ability to capture attention. Theeuwes (1991) demonstrated that abrupt object onsets and offsets capture attention in a visual search task even when they are nonpredictive of the target location. Theeuwes had his participants search for a target letter among three distractor letters. In Experiment 1, the onset of a black rectangle was randomly associated with the location of each letter in the display. When the onset occurred next to the location of the target, search for the target was facilitated. When the onset occurred next to a distractor, search for the target was slowed. Theeuwes interpreted this RT difference as being due to the onset's capturing attention. In Experiment 2, Theeuwes found that the offset of a black rectangle produced a similar effect. When attention could not be focused in advance, offsets were just as effective as onsets in capturing attention. These two experiments suggest that both the onset and the offset of an object can cause a shift of spatial attention.
Many studies have shown that after a location is attended, this location is then inhibited, a phenomenon known as inhibition of return, or IOR (see Klein, 2000, for a review). Recent work by Samuel and Weiner (2001) demonstrated a spatial shift of attention to the location of both object onsets and offsets in an IOR paradigm. In a complex display, a small red or blue box or disk could onset or offset at the same location as the subsequent target or at locations with different distances from the target. RTs for the detection of the target at the same location as a previous onset or offset were slowed. As compared with onsets, the inhibition observed after offsets was spatially narrower and did not follow the typical time course of IOR (with inhibition occurring as soon as $80 \mathrm{msec}$ after the offset). Nonetheless, inhibition was observed after an offset that was location dependent, suggesting that offsets did indeed cause a shift of spatial attention. Samuel and Weiner attributed this time course difference to quick attentional disengagement after an offset has occurred, since there is no object remaining to be processed. Pratt and Hirshhorn (2003) found a similar pattern of results, using simultaneous onset and offset cues. Both onset and offset cues captured covert attention, but IOR was observed earlier for offset cues, indicating the quick disengagement of attention. In addition, Pratt and McAuliffe (2001) observed that the onset and the offset of a disk created equally strong early facilitation effects and late inhibitory effects, suggesting that covert attention shifts are caused by both events and that both of these transient types capture attention equally well.

Rather than measuring RT, Chastain and Cheal (2001) used accuracy of detecting a briefly presented target to infer attentional capture by onsets and offsets. In a predisplay presented before the target screen, either a line segment could onset or the horizontal arm of a cross figure could offset (partial offset). When the onset/offset occurred at the location of the subsequent target, accuracy was improved. This was true whether the target was created by an onset or an offset, ruling out that capture in this case was due to participants' adopting an attentional set for either singleton.

Finally, Watson and Humphreys (1995) found that partial contour onsets and offsets (the appearance or disappearance of part of an object) could both capture attention and guide attention equally well in a visual search task. For example, in Experiment 5, the target letter A could be formed by the onset of a line segment to an inverted $\mathrm{U}$ or the offset of a line segment of a figure eight. Search was more efficient when the target was formed by an onset or offset than when the target was a static element in the display. Contour onsets and offsets did not differ in their ability to attract attention. However, display size effects were observed for both contour onsets and offsets, suggesting that onsets that create new objects might have a special status over partial onsets.

Of course, there are alternative accounts to explain attentional capture other than bottom-up, stimulus-driven 
accounts. The most studied alternative is the contingent capture hypothesis of Folk and colleagues (Folk \& Remington, 1998; Folk, Remington, \& Johnston, 1992; Folk, Remington, \& Wright, 1994). In a series of studies, Folk and colleagues showed that attentional capture depends critically on top-down expectations. For example, a color cue will capture attention only when the target of search is a color singleton, and an onset cue will capture attention only when the target is an onset singleton. In studies of attentional capture, it is important to keep such contingencies in mind, especially given evidence that nonobvious stimulus properties in the display may create unwanted attentional sets (Gibson \& Kelsey, 1998). These attentional sets can then encourage attention shifts that may be mistaken for stimulus-driven capture. Atchley, Kramer, and Hillstrom (2000) demonstrated that capture by both onset and offset transients is sensitive to such contingencies. In two experiments, Atchley et al. found that the ability of each type of distractor (onset/offset) to capture attention was contingent upon the nature of the target display. Four small dots could onset or offset around either the target position or one of the distractor positions. Onsets captured attention when items in the target display appeared as onsets, and offsets captured attention when the target display was created by offsetting line segments. However, another experiment revealed capture by onsets and offsets when neither the nature of the target nor the nature of the distractor (onset or offset) could be predicted, making it unlikely that an attentional set for either onsets or offsets could be adopted (however, it does not rule out the possibility that participants were adopting an attentional set for both types of distractors or transients in general).

Taken together, these results suggest that both the appearance and the disappearance of an object can capture attention, even when the change is nonpredictive of the target location. In the complex, occlusion-rich environments we navigate through every day, it would be beneficial for the visual system to be concerned with both object onsets and object offsets. The offset of one object is often associated with the onset of an object that was being occluded. The onset of a new object causes the offset of whatever is behind it. There is converging evidence from different paradigms suggesting that covert attention is influenced by both the appearance and the disappearance of an object. In addition to covert measures of attention, the effect of abrupt object onsets has been examined using overt measures of attention.

\section{Eye Movements and Onsets/Offsets}

Further evidence for the ability of onsets to cause a spatial shift of attention is that abrupt object onsets can cause involuntary overt orienting toward the location of an onset. In what has been termed oculomotor capture, abrupt object onsets can interrupt goal-directed eye movements. Irwin, Colcombe, Kramer, and Hahn (2000), Kramer, Cassavaugh, Irwin, Peterson, and Hahn (2001), Kramer, Hahn, Irwin, and Theeuwes (2000), Theeuwes, Kramer, Hahn, and Irwin (1998), and Theeuwes, Kramer,
Hahn, Irwin, and Zelinsky (1999) have demonstrated that when participants were asked to make eye movements to a unique color singleton in a display in the presence of the addition of a new object, they first moved their eyes to the new object and then to the color singleton on a large proportion of the trials. Surprisingly, the participants were generally unaware that new objects were being added to the display and were unaware of making saccades to them. Saccades made to a new object appear to be reflexive in nature, with saccadic latencies being shorter when the eyes went to the onset than when they went directly to the target. When the eyes erroneously moved to the onset, rather than to the target, fixations were extremely brief before the eyes went to the correct location, suggesting the parallel programming of two saccades: one to the target and one to the task-irrelevant object.

The fact that onsets demonstrate a greater ability to capture the eyes, as compared with color or luminance singletons, has led some to conclude that, like covert attention (Jonides \& Yantis, 1988), the oculomotor system gives special priority to new objects appearing in the environment (Irwin et al., 2000). However, conclusions based on such disparate singleton types might not be particularly meaningful. A comparison between onset and offset transients may be the best way to test whether onsets are, indeed, unique in their ability to capture the eyes, since pixel for pixel, the amount of display change is equated in both cases. For this reason, onsets and offsets were investigated in the present study with regard to their ability to capture the eyes. Although the oculomotor consequences of abrupt object onsets seem clear, the consequences of abrupt object offsets are uncertain. A priori, one might expect offsets to have oculomotor consequences similar to those of onsets, given that both have had similar consequences when covert attention has been examined.

However, the attentional capture and IOR literature is not unequivocal. Whereas some studies have indicated that onsets and offsets have identical effects on covert attention (Chastain \& Cheal, 2001; Pratt \& McAuliffe, 2001; Watson \& Humphreys, 1995), others have suggested that this is true only under certain conditions (Atchley et al., 2000; Theeuwes, 1991), and still others have suggested that the attentional effects of onsets and offsets might have different strengths (Miller, 1989) or time courses (Samuel \& Weiner, 2001). The consensus of the literature reviewed is consistent with the fact that both events influence the allocation of covert attention, and there appears to be a strong, if not obligatory, coupling of covert attention and eye movements (Deubel \& Schneider, 1996; Kowler, Anderson, Dosher, \& Blaser, 1995; Peterson, Kramer, \& Irwin, 2004). If the attentional system treats both of these events similarly, it is reasonable to assume that the oculomotor system will do the same. On the other hand, since a change involving a complete offset leaves no object remaining in the display, it may be that eye movements toward the location of an offset will rarely be made. In this case, a partial offset leaving some object remaining in the display might capture the eyes, even though the 
complete offset of an object might not. In addition, it may be that the oculomotor system is more concerned with the appearance of a new object, since an abrupt object onset may require immediate action.

\section{Overview of Experiments}

We present a series of experiments in which we examined the oculomotor consequences of object onsets and offsets during a visual search task. Here, we used a rigorous definition of capture, in which attention to the transient would always be detrimental to performance (Remington, Johnston, \& Yantis, 1992). It has been suggested that participants might organize their search around salient singletons in the display when these singletons are sometimes associated with the target, leading to attentional prioritization of these singletons (Todd \& Kramer, 1994). A strong definition of capture argues that attentional capture occurs even when there is no chance that the attentioncapturing feature might be the target. Therefore, the onsets and offsets in the series of experiments reported here never coincided with the target location. We recognize that this is not the only definition of capture. Indeed, this may be a contributing factor to why, in the covert experiments we report here, we find that offsets demonstrate little or no covert attentional capture.

In each experiment, onsets dominated oculomotor capture, with the eyes going to the location of the offset very infrequently. In Experiment 1, we examined the oculomotor consequences of complete object onsets and offsets. In Experiment 2, we studied partial contour onsets and offsets, so that the offset of an object left a stimulus to which attention could be directed. The direction of the luminance change accompanying onsets and offsets was reversed in Experiment 3, and in Experiment 4, the onset/ offset occurred prior to the color change indicating the target location. Only offsets occurring before the color change indicating the target location were able to disrupt eye movements to the target, although the magnitude of this effect was small. In Experiment 5, we reexamined the effect of onset/offset transients on the control of covert attention. Antipredictive offsets demonstrated little cost when an offset occurred around a distractor letter in a visual search task, whereas onsets slowed RTs. These results are most consistent with a new-object theory of attentional capture.

\section{EXPERIMENT 1}

To determine whether the appearance and disappearance of an object have similar effects on oculomotor behavior in an overt visual search task, an experiment was performed with a design similar to that in the oculomotor capture studies of Irwin et al. (2000), Kramer et al. (2001), Kramer et al. (2000), Theeuwes et al. (1998), and Theeuwes et al. (1999). Participants were asked to make a goal-directed saccade to a uniquely colored object and determine the identity of a target letter contained within it. On some trials, a new, task-irrelevant object was added to the display, and it was expected that the new object should capture the eyes on a substantial proportion of trials, in accord with prior research. In addition to these onset trials, some trials featured the disappearance of a task-irrelevant object. If the offset of an object has the ability to capture attention, oculomotor behavior would be expected to be affected when a goal-directed saccade must be made in the presence of the disappearance of an irrelevant object.

\section{Method}

Participants. Twelve participants ( 4 males and 8 females), ranging in age from 18 to 31 years, were paid $\$ 6$ for their participation. All the participants demonstrated normal color vision, as measured by the Ishihara Color Blindness Test, and normal visual acuity, as measured by Snellen charts.

Apparatus. A Pentium-based computer with a 21-in. SVGA color monitor was used to present all the stimuli. The participants' eye movements were recorded with an EyeLink eye tracker $(250-\mathrm{Hz}$ temporal resolution, $0.2^{\circ}$ spatial resolution). An eye movement was classified as a saccade if acceleration exceeded $8,000 \mathrm{deg} / \mathrm{sec}^{2}$ and speed exceeded $30 \mathrm{deg} / \mathrm{sec}$ or distance exceeded $0.2^{\circ}$. A chinrest was used to stabilize head position. The same apparatus was used for Experiments 1-4.

Stimuli. The participants viewed displays containing five or six gray circles arranged around the perimeter of an imaginary circle with a radius of $7.9^{\circ}$ (see Figure 1). These unfilled circles measured $2.64^{\circ}$ in diameter and $0.075^{\circ}$ thick. Each gray circle contained a small gray figure eight premask $\left(0.15^{\circ} \times 0.30^{\circ}\right)$. Circles and premasks could appear at clock positions of $1,3,5,7,9$, and 11 o'clock. A fixation cross measuring $0.8^{\circ}$ was located at the center of the screen. After $1 \mathrm{sec}$, the fixation cross was extinguished, and the color of all the circles except one changed to red. Simultaneously with the color change, the figure eight premasks within each circle were replaced with letters. These letters were too small to discriminate without foveation. The remaining gray circle always contained either the letter $\mathrm{C}$ or a reversed $\mathrm{C}$. All the other circles contained one letter drawn randomly without replacement from the pool of letters E, F, H, P, $\mathrm{S}$, and $\mathrm{U}$.

Four types of trials occurred with equal probability. Two of these were control trials, in which no additional changes were made to the display other than the color change and the replacement of premasks with letters. These two control trial types differed in the number of circles and premasks. Half of the control trials contained five circles and premasks in the display (five-static), and half contained six (sixstatic). To control for the number of circles in the initial and final displays, data from the five-static and the six-static conditions were combined. In the onset condition, the initial display contained five circles and premasks, and simultaneously with the color change, an additional red circle and letter were added to the display. The new circle was always task irrelevant and never contained the target. In the offset condition, the initial display contained six circles and premasks, and simultaneously with the color change, one circle and premask was removed from the display. In both experimental conditions, the transient distractor (onset or offset) could occur $30^{\circ}, 60^{\circ}$, or $180^{\circ}$ from the target location. In the five-static control condition, the position containing no circle could also occur at these distances from the target.

Procedure. The EyeLink eye tracker was strapped to the participant's head, the camera was adjusted to center the participant's pupil, and calibration was performed. Eye position was recorded using only the left eye. The participants placed their head in a chinrest approximately $76 \mathrm{~cm}$ from the monitor to stabilize head position. The participants were instructed to maintain fixation until the color change occurred. Once the color change had occurred, they were to move their eyes to the uniquely colored circle and judge whether the circle contained a $\mathrm{C}$ or a reversed $\mathrm{C}$. A tone informed the participants if they moved their eyes too soon (before the color change). A tone also indicated an incorrect response to the target identity. Responses 
Onset Distractor

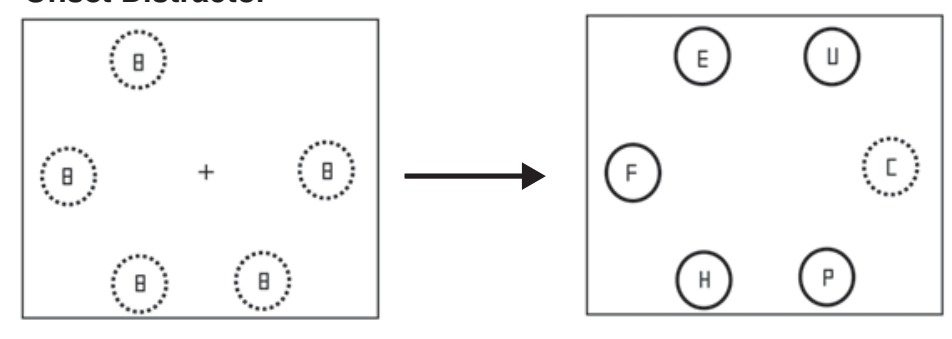

Offset Distractor

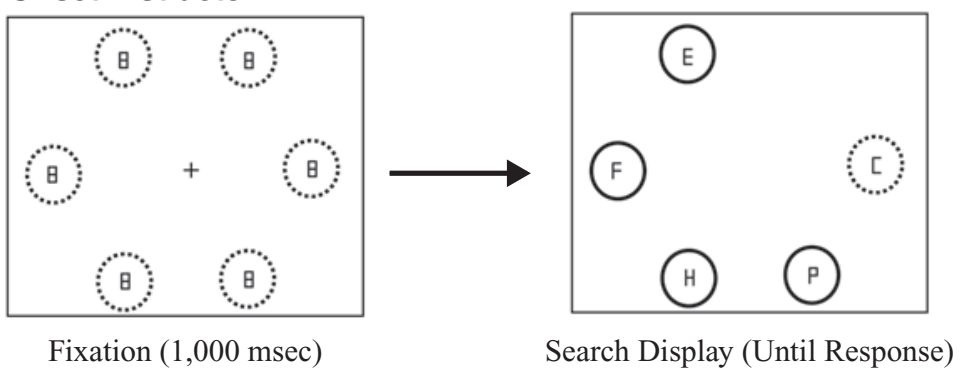

Figure 1. Example of the displays viewed in Experiment 1. Simultaneously with the color change, an object could be either added or deleted from the display. Circles in the display were initially gray (depicted in the figure as dotted), and all but one changed color to red (depicted as solid).

were made by pressing the "z" key or the "/" key on the computer keyboard. Response mappings were counterbalanced across participants. Each trial was self-initiated, with the participant pressing any key to begin a trial. The participants completed four blocks of 120 trials each. An additional block of 10 practice trials was completed before the first experimental block. The four trial types (five-static, six-static, onset, and offset) appeared randomly within each block of trials. With the random intermixing of the two static and the two dynamic displays, the participants could not anticipate whether a trial would contain an onset, an offset, or neither. Both speed and accuracy were stressed, and the participants received feedback about their performance after each block of trials.

\section{Results and Discussion}

Accuracy for determining the identity of the character (C or reversed C) at the target location was high (approximately $98 \%$ ). Since error rates were so low, they were not further analyzed. Overall, 14\% of all the trials were rejected, due to the participants' failing to maintain fixation or making incorrect responses to the target or because of technical problems (such as the eye tracker losing the participant's pupil or needing to be recalibrated). These trials were excluded from analysis.

Oculomotor behavior. Oculomotor behavior was the primary measure of interest. The proportion of trials on which the eyes went directly to the target after the color change was used to measure the disruption of goaldirected saccades. If a transient distractor has the ability to capture the eyes, it was expected that the initial saccade would go directly to the color singleton target on a smaller proportion of trials, as compared with the control condition. A saccade was classified as going to a particular item in the display if the first saccade after the color change fell within a $30^{\circ}$ wedge centered on the item and extending to the fixation point at the center of the screen. The endpoint of the initial saccade also had to land outside of a $2^{\circ}$ circular region surrounding the fixation point.

Figure 2 illustrates the proportion of trials on which the first saccade went to either the target or the transient distractor for each condition. The proportion of trials on which the eyes went directly to the target after the color change were entered into a one-way repeated measures analysis of variance (ANOVA), with condition as the factor and control, offset, and onset trials as the three levels of the factor. This ANOVA revealed a significant difference in the disruption of goal-directed saccades among conditions $[F(2,22)=27.63, p<.001]$. All the statistical tests between the experimental and the control conditions used a familywise error rate of .05, with an alpha level of .025 for each test of the experimental and control conditions. Planned comparisons of each experimental condition with the control condition revealed that the onset of a new object disrupted saccades to the target, with the eyes going directly to the target on a smaller proportion of trials $[F(1,11)=26.43, p<.001]$, whereas the offset of an object had no effect $[F(1,11)=1.04, p=.330]$. Further analysis revealed that on a large percentage of trials $(27 \%)$, the eyes erroneously went to the onset item and then to the target location. The eyes almost never went to the location of the offset item (fewer than $1 \%$ of the trials). Oculomotor behavior in the presence of an onset was consistent with previous research (Irwin et al., 2000; Kramer et al., 2001; Kramer et al., 2000; Theeuwes et al., 1998; Theeuwes et al., 1999). The onset of a new object in the display demonstrated the ability to capture the eyes, 


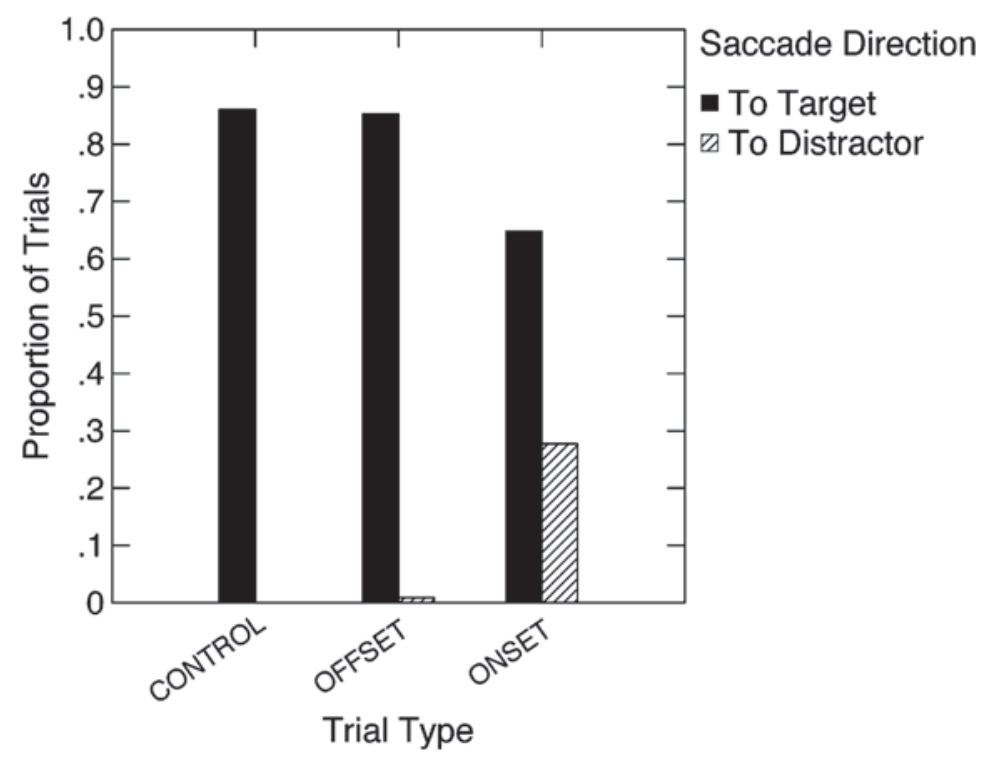

Figure 2. Mean proportion of trials on which the first saccade went to the target or the distractor for each condition in Experiment 1.

causing an overt shift of attention toward the location of the onset item. The offset of an object, however, did not disrupt goal-directed eye movements to the color singleton target and did not demonstrate the power to capture the eyes.

Saccadic latencies. Saccadic latency was measured as the amount of time between the color change indicating the target location and the initiation of the first saccade. Table 1 contains saccadic latency and RT data for this experiment, as well as for Experiments 2 and 3.

To examine whether an onset or an offset had an effect on eye movements when the eyes went to the target, saccade latencies of those trials on which the first saccade went to the target were entered into a one-way repeated measures ANOVA, with condition as the factor and control, offset, and onset as the three levels of the factor. This analysis indicated a significant difference in saccadic latencies among conditions $[F(2,22)=4.23$, $p<.05]$. Further analysis revealed a trend for latencies to be slightly longer in the presence of an onset on trials on

Table 1

Mean Saccadic Latency and Reaction Time (in Milliseconds) for Each Condition in Experiments 1, 2, and 3 for Trials on Which the Eyes Went Directly to the Target

\begin{tabular}{lccc}
\hline Experiment & Control & Offset & Onset \\
\hline 1 Saccadic latency & 283 & 285 & \\
$\quad$ Reaction time & 830 & 837 & 864 \\
2 Saccadic latency & 255 & 255 & 254 \\
$\quad$ Reaction time & 765 & 764 & 761 \\
3 Saccadic latency & 234 & 234 & 234 \\
Reaction time & 755 & 762 & 762 \\
\hline
\end{tabular}

which the eyes went directly to the target $[F(1,11)=5.09$, $p=.045]$. No such trend existed for offsets $[F(1,11)=$ $0.373, p=.554]$.

Latencies for saccades going to the onset in the display were approximately $75 \mathrm{msec}$ shorter than those for saccades that went directly to the target [219.6 vs. $294.2 \mathrm{msec}$; $t(11)=7.15, p<.001]$. These short latencies for when the eyes go to the onset are evidence of the reflexive nature of these eye movements. Fixations of the eyes at the onset were very brief (average of $108 \mathrm{msec}$ across participants), suggesting that two eye movements were programmed in parallel: one to the location of the color singleton and one to the location of the onset (Theeuwes et al., 1999).

Reaction time. RT was measured as the time between the color change indicating the target location and the time of the participant's manual response to the identity of the target. An analysis identical to the one used to examine the latency data was performed on RT, using only the trials on which the eyes went directly to the target. This allows for the examination of whether the onset or offset of a circle had an effect on covert attention even when the eyes went to the target. This analysis revealed a significant effect of condition $[F(2,22)=6.85, p<.01]$. Even when the eyes went directly to the target, RT to identify the target was lengthened in the presence of an onset $[F(1,11)=$ $8.60, p=.014]$. The presence of an offset did not affect RT $[F(1,11)=1.03, p=.329]$. A paired $t$ test revealed significantly longer RTs on those trials on which the eyes first went to the onset item, as compared with when the eyes went directly to the target [972.9 vs. $862.2 \mathrm{msec}$; $t(11)=6.19, p<.001]$. This difference in RT (approximately $111 \mathrm{msec}$ ) can be accounted for by the time spent fixating the onset distractor and the additional saccade needed to foveate the target. 
Longer RTs in the onset condition even when the eyes went directly to the target indicate that even when the onset item did not capture the eyes, responses were still influenced by the appearance of the new object. It should be noted that the observed RT difference does not necessarily imply a covert shift of attention and is indistinguishable from nonspatial filtering costs (Folk \& Remington, 1998). However, the finding of IOR at the location of the onset even when the eyes go directly to the target (Godijn $\&$ Theeuwes, 2002) suggests that covert attention can go to the onset even when the eyes do not (but see also Peterson et al., 2004). The lack of RT difference in the offset condition suggests that covert attention was not affected by the offset of an object in the display.

The findings of Experiment 1 are consistent with those in previous research with regard to oculomotor behavior and RT when participants search for a color singleton target in the presence of an abrupt object onset. The participants' eyes were captured by the onset on a substantial proportion of the trials. Fixations were short when the eyes went to the onset. These fixations were too short for programming a new saccade to the target, suggesting the parallel programming of both a reflexive and a goal-directed saccade (McPeek, Skavenski, \& Nakayama, 2000). Surprisingly, although offsets have been shown to capture covert attention just as well as onsets do (e.g., Chastain \& Cheal, 2001; Pratt \& McAuliffe, 2001; Theeuwes, 1991), oculomotor behavior and RTs were unaffected by the presence of an offset, suggesting that neither overt attention nor covert attention was captured by the offset of an item from the display.

\section{EXPERIMENT 2}

Experiment 1 demonstrated that when an object disappeared from the display, participants rarely made saccades to the location of the offset. This may not be surprising, considering that the offset of an object created an area in the display containing very little information. There was no possibility that the location of the offset could contain the target, since there was nothing left at that location in Experiment 1 . In addition, there was no saccade target toward which to program an eye movement. It has also been proposed that offsets shift attention to objects, rather than to a region in space (Miller, 1989). Without an actual target object, it could be that attention has little reason to shift to the location of the offset. To test these hypotheses, the offsets in Experiment 2 were not complete offsets but, instead, were partial contour offsets. ${ }^{1}$ A location and a possible saccade target remained after the gray circle offset. Similarly, the onsets were not complete onsets but were partial contour onsets (see Figure 3).

\section{Method}

Participants. Twelve participants ( 6 males and 6 females), ranging in age from 18 to 27 years, were paid $\$ 6$ for their participation. All the participants demonstrated normal color vision, as measured by the Ishihara Color Blindness Test, and normal visual acuity, as measured by Snellen charts.

\section{Contour Onset Distractor}

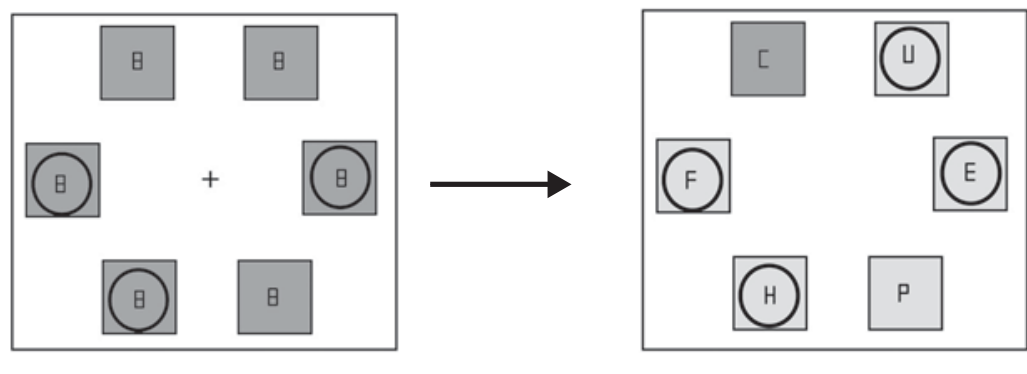

\section{Contour Offset Distractor}

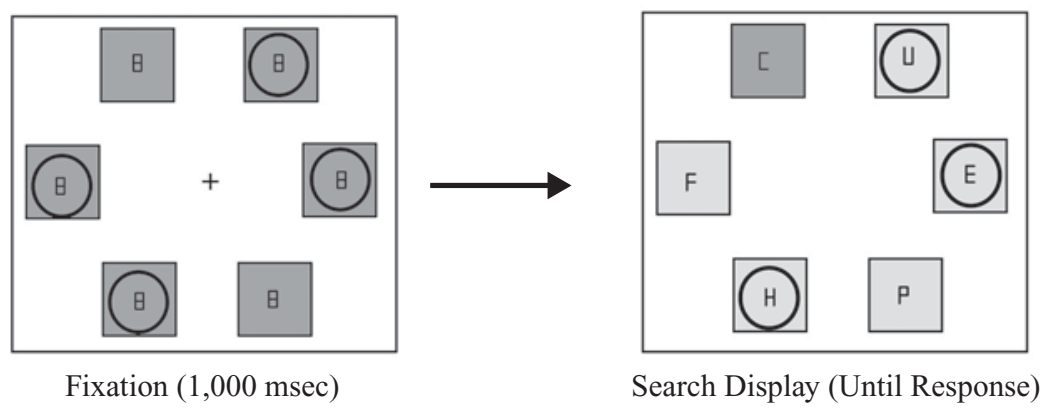

Figure 3. Example of the displays viewed in Experiment 2. Color patches were initially green (depicted as dark gray), and all but one changed color to red (depicted as light gray). Simultaneously with the color change, a circle could be added or deleted from the display. 
Stimuli. The participants viewed displays containing six square color patches $\left(3.0^{\circ} \times 3.0^{\circ}\right)$ equally spaced around the perimeter of an imaginary circle with a radius of $7.9^{\circ}$. As in Experiment 1, all the color patches contained premasks that were replaced by letters after $1 \mathrm{sec}$. The color patches were initially red $\left(1.2 \mathrm{~cd} / \mathrm{m}^{2}\right)$, and all but one changed color to green $\left(1.6 \mathrm{~cd} / \mathrm{m}^{2}\right)$. These colors were psychophysically matched for luminance, using two observers. Three or four gray circles with the same dimensions as those in Experiment 1 could also appear in the initial display. On $45 \%$ of the trials, a new circle would appear simultaneously with the color change. On $45 \%$ of the trials, a circle would offset simultaneously with the color change. The number of circles in the display stayed the same on $10 \%$ of the trials, which served as controls. In all the control trials, three circles appeared in the display. On half of all the trials, a circle in the display was located around the position of the target. However, the onset/offset of a circle never occurred at the target location.

Procedure. The procedure was identical to that in Experiment 1. The participants were instructed to move their eyes to the color singleton as quickly as possible after the color change and to indicate whether the target location contained a $\mathrm{C}$ or a reversed $\mathrm{C}$. The participants completed three blocks of 132 trials and received speed and accuracy feedback after each block.

\section{Results and Discussion}

Accuracy for determining the identity of the character at the target location was high (approximately 97\%). Since error rates were so low, they were not further analyzed. Overall, $17 \%$ of the trials were rejected, due to participants' failing to maintain fixation or responding incorrectly to the target or because of technical problems. These trials were excluded from analysis.

Oculomotor behavior. Figure 4 illustrates the proportion of trials on which the first saccade went to either the target or the transient distractor. A one-way repeated measures ANOVA was performed on the proportion of trials on which the eyes went directly to the target, with trial type as the factor and control, offset, and onset trials as the three levels of the factor. This analysis revealed a significant difference in the disruption of goal-directed saccades among trial types $[F(2,22)=8.63, p<.01]$. Planned comparisons between each experimental condition and the control condition showed that whereas onsets disrupted goal-directed saccades $[F(1,11)=9.08, p=$ $.012]$, offsets did not $[F(1,11)=0.73, p=.411]$. Oculomotor capture was noticeably decreased, as compared with Experiment 1, although this difference failed to reach significance. ${ }^{2}$ The eyes first went to the location of the onset on $15.8 \%$ of the onset trials, as compared with $27.2 \%$ in Experiment 1 . The eyes very rarely went to the location of the offset (fewer than $2 \%$ of all the trials).

Saccadic latencies. Unlike in Experiment 1, an analysis of only those eye movements that went directly to the target revealed no significant difference between conditions $[F(2,22)=0.132, p=.877]$. In Experiment 1 , the onset caused prolonged latencies when the eyes went to the target, as compared with the control condition. No such lengthening was observed in Experiment 2 (and the subsequent experiments reported here). In a similar paradigm, Theeuwes et al. (1999) also found no difference in saccadic latencies between these conditions, with a saccadic latency of $234 \mathrm{msec}$ in the control condition and $237 \mathrm{msec}$ in the 0 -msec stimulus onset asynchrony (SOA) onset condition, whereas Irwin et al. (2000) did find a difference. At this point, it is unclear why this latency difference is sometimes present and sometimes not. However, in accord with the previous experiment and the literature, a comparison of saccadic latencies in the onset condition between saccades that went directly to the target and saccades that erroneously went to the onset again indicated

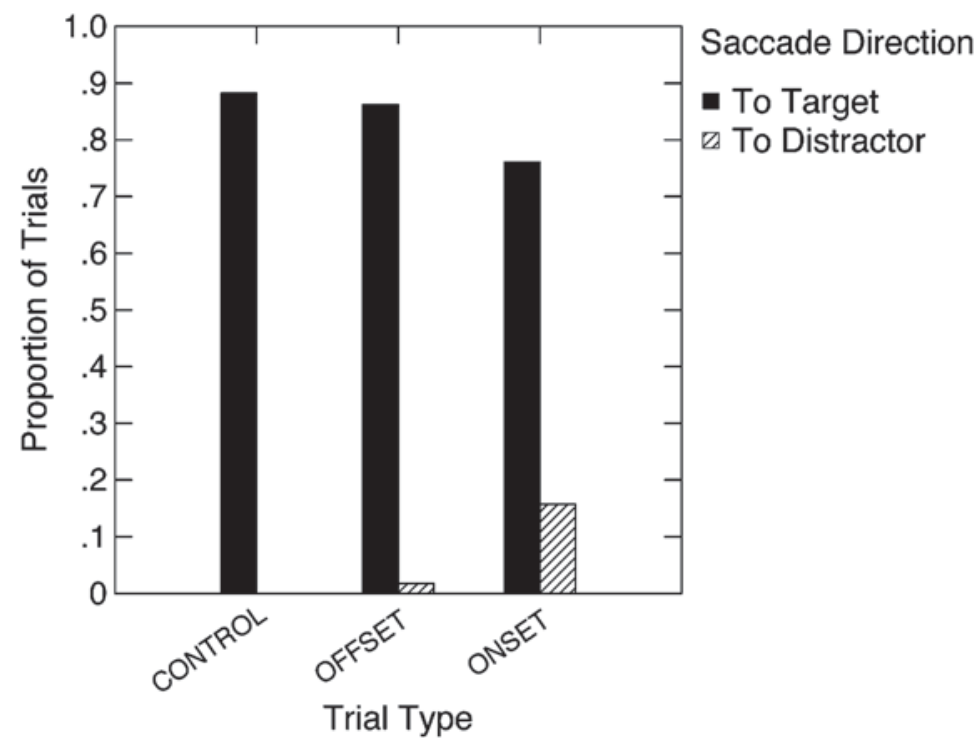

Figure 4. Mean proportion of trials on which the first saccade went to the target or the distractor for each condition in Experiment 2. 
a significant difference [216.1 vs. $256.5 \mathrm{msec} ; t(10)=$ $-14.625, p<.001] .^{3}$ When the eyes went to the onset distractor, latencies were approximately $40 \mathrm{msec}$ shorter.

Reaction time. An analysis of only those trials on which the eyes went directly to the target also revealed no RT difference $[F(2,22)=0.118, p=.889]$ between conditions. However, as in Experiment 1, an RT difference between those trials on which the eyes went directly to the target in the onset condition $(767.14 \mathrm{msec})$ and those on which the eyes first went to the onset $(863.25 \mathrm{msec})$ proved to be significant $[t(10)=-20.03, p<.001]$.

The lack of a significant difference in RT between trial types on those trials on which the eyes went directly to the target could be accounted for if the onsets in Experiment 2 had less ability to capture attention (i.e., trials on which the onset captured attention made up a smaller proportion in the overall mix). Onsets might have decreased power to capture attention because of the greater amount of change in the display in Experiment 2 than in Experiment 1 (Martin-Emerson \& Kramer, 1997; Miller, 1989). Rather than thin circles changing color, large color patches changed color simultaneously with the onset/offset of a circle. The greater complexity of the display might have made the onset/offset of a circle less salient (Nikolic, Orr, \& Sarter, 2004). In Experiment 2, onsets demonstrated a decreased (although not significantly so) ability to capture the eyes. These results might suggest that eye movement direction, rather than latency or RT measures, is a more sensitive measure of capture. Irwin et al. (2000) suggested that RT differences in such tasks are due largely to corrective eye movements as a result of refixations. Focusing only on those eye movements directed to the target may not provide an adequate measure of capture in this overt eye movement task.

Another possibility for somewhat decreased capture is the different nature of the two onsets. In Experiment 1, the onset might have created a stronger perception of a new object. It has been proposed that the perception of a new object captures attention (Yantis \& Hillstrom, 1994; Yantis \& Jonides, 1996). Rather than an object's appearing at a previously unoccupied location, the onset in Experiment 2 occurred at an already existing location, possibly decreasing the perception of the object as new. Watson and Humphreys (1995) found that for contour onsets that did not create a new object but changed the identity of an old item, attentional capture was not as strong as in some studies in which complete onsets were used. The same phenomenon might explain why the eyes went to the onset more often in Experiment 1 than in Experiment 2.

The RT difference between trials on which the eyes went to the target and those on which the eyes went to the onset did not differ significantly between Experiments 1 and 2 [111 vs. $96 \mathrm{msec} ; t(12.6)=0.78, p=.452]$. Whether decreased capture is a result of greater change in the display or the different types of onsets in the two experiments, this lack of difference suggests that onset capture was of the same nature in both experiments, with a smaller proportion of saccades going to the onset in Experiment 2. In other words, there were no qualitative differences between the distracting effects of these two onset types (in terms of RT); onset distractors simply attracted the eyes less frequently in Experiment 2.

The results of Experiment 2 show that even when the eyes have a target to program an eye movement to, the offset of an object demonstrates no oculomotor capture. Onsets again were able to attract the eyes, but their power to do so was somewhat decreased. This decrease in the onsets' ability to attract attention is observable not only in fewer eye movements first going to the location of the onset, but also in the lack of a significant RT effect on those trials on which the eyes went directly to the target. The only RT effect that reached significance was the extra time needed to saccade to the target after the eyes erroneously had gone to the onset item.

\section{EXPERIMENT 3}

Experiment 2 demonstrated that partial offsets' leaving a location in the display for the eyes to move to did not capture the eyes. Partial onsets, however, still captured the eyes. One potential confound in the previous experiments might be that the occurrence of an onset was always signaled by a luminance increment (a light gray circle appearing on a darker background), whereas the offset was always signaled by a luminance decrease. It is possible that the direction of this luminance change, and not the onset itself, captured the eyes. To examine this possibility, in Experiment 3, the direction of the luminance change accompanying onsets and offsets was reversed. Black circles offset from brighter color patches, causing a luminance increase at offset locations and a luminance decrease at onset locations. If the new objectness of the onset is what truly captures the eyes, onsets should still show greater oculomotor capture, as compared with offsets. If the direction of the luminance change matters, it would be expected that offsets would capture the eyes when they created a luminance increment.

\section{Method}

Participants. Twelve participants (4 males and 8 females), ranging in age from 18 to 24 years, were paid $\$ 8$ for their participation. All the participants demonstrated normal color vision, as measured by the Ishihara Color Blindness Test, and normal visual acuity, as measured by Snellen charts.

Stimuli. The stimuli were almost identical to those in the previous experiment, with the exception of display colors. Black circles $\left(1.12 \mathrm{~cd} / \mathrm{m}^{2}\right)$ could onset or offset from red/green color patches. These colors were matched for luminance by each observer before the experiment, with the participants matching the luminance of green to red with a luminance of $8.75 \mathrm{~cd} / \mathrm{m}^{2}$.

Procedure. The procedure was identical to that in Experiments 1 and 2. The participants were instructed to move their eyes to the color singleton as quickly as possible after the color change and to indicate whether the target location contained a $\mathrm{C}$ or a reversed $\mathrm{C}$. The participants completed three blocks of 100 trials and received speed and accuracy feedback after every 15 trials.

\section{Results and Discussion}

Accuracy for determining the identity of the character at the target location was high (approximately 97\%). Since error rates were so low, they were not further ana- 


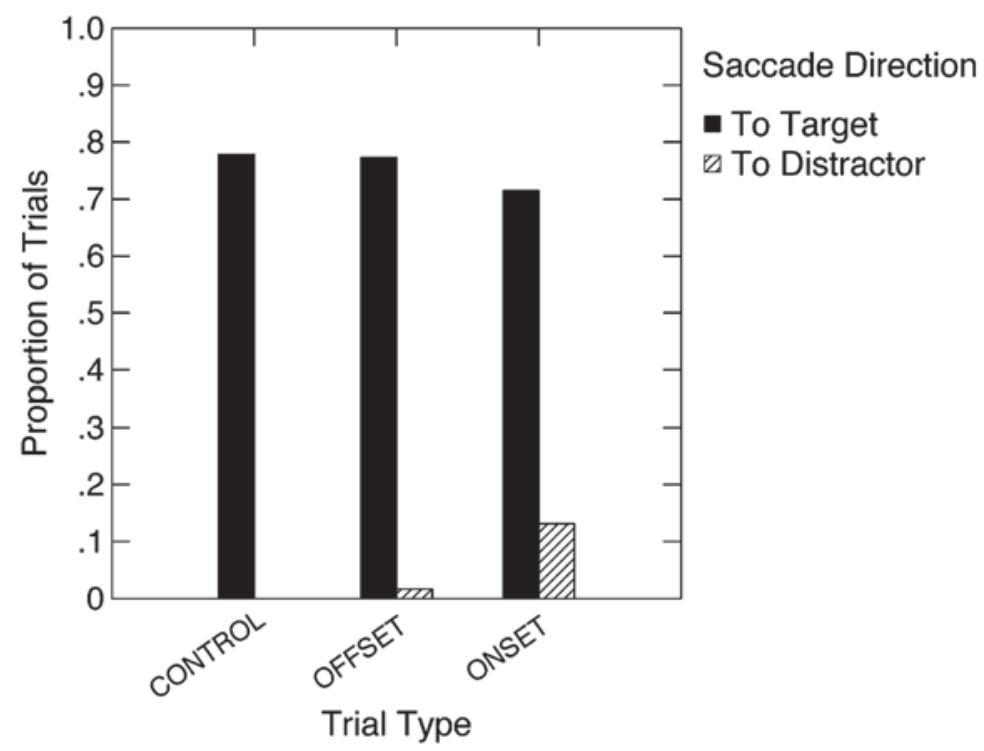

Figure 5. Mean proportion of trials on which the first saccade went to the target or the distractor for each condition in Experiment 3.

lyzed. Overall, $13 \%$ of the trials were rejected, due to participants failing to maintain fixation or responding incorrectly to the target or technical problems. These trials were excluded from analysis.

Oculomotor behavior. Figure 5 illustrates the proportion of trials on which the first saccade went to either the target or the transient distractor. A one-way repeated measures ANOVA was performed on the proportion of trials on which the eyes went directly to the target, with trial type as the factor and control, offset, and onset trials as the three levels of the factor. This analysis revealed a significant difference in the disruption of goal-directed saccades among trial types $[F(2,22)=3.77, p<.05]$. Planned comparisons between each experimental condition and the control condition showed that whereas onsets disrupted goal-directed saccades $[F(1,11)=6.25, p=$ .029], offsets did not $[F(1,11)=0.04, p=.844]$. The eyes first went to the location of the onset on $13 \%$ of the onset trials. The eyes very rarely went to the location of the offset (fewer than $2 \%$ of all the trials).

Saccadic latencies. A one-way repeated measures ANOVA performed on saccadic latencies for only those eye movements that went directly to the target revealed no significant difference between conditions $[F(2,22)=$ $0.085, p=.92]$. A comparison of saccadic latencies in the onset condition between saccades that went directly to the target and saccades that erroneously went to the onset indicated a significant difference [185.9 vs. $234.4 \mathrm{msec} ; t(10)=$ $-10.49, p<.001]$. When the eyes went to the onset distractor, latencies were approximately $48 \mathrm{msec}$ shorter.

Reaction time. A one-way repeated measures ANOVA performed on RT for those trials on which the eyes went directly to the target revealed no difference $[F(2,22)=$ 2.27, $p=.127]$. An RT difference between those trials on which the eyes went directly to the target in the onset condition (762.19 msec) and those on which the eyes first went to the onset $(833.03 \mathrm{msec})$ proved to be significant $[t(11)=-5.02, p<.001]$.

The results of Experiment 3 indicate that oculomotor capture by onsets does not require the onset to be accompanied by a luminance increment. Although this was a confound in Experiments 1 and 2, the present results suggest that it is the new objectness, and not the increase in luminance, that is critical in oculomotor capture. Even offsets that create an increase in luminance show no ability to capture the eyes.

\section{EXPERIMENT 4}

One important distinction between Experiments 1-3 and studies that have shown covert attentional capture for onsets and offsets is that in our paradigm, any exogenous capture by distractors must compete with strong, goaldirected shifts of attention to the color singleton. In Experiment 4, we used a negative SOA to investigate the possibility that in the absence of simultaneous goal-directed shifts of attention, offsets might capture the eyes.

\section{Method}

Participants. Twenty-four participants (12 males and $12 \mathrm{fe}-$ males), ranging in age from 18 to 28 years, were paid $\$ 6$ for their participation. All the participants demonstrated normal color vision, as measured by the Ishihara Color Blindness Test, and normal visual acuity, as measured by Snellen charts.

Stimuli. Displays were identical to those in Experiment 2, with one exception. In addition to the onset and offset conditions, two new experimental conditions were added in which the onset or the offset could occur with an SOA of $-175 \mathrm{msec}$. This SOA was chosen on the basis of the results of Theeuwes (1991), in which large offset cuing effects were obtained using an approximately equal SOA $(160 \mathrm{msec})$. On these trials, the onset/offset of a circle would occur, 
and $175 \mathrm{msec}$ later, the fixation point was extinguished and all color patches except one changed color. The experiment consisted of $45 \%$ onset trials, $45 \%$ offset trials, and $10 \%$ control trials. For each experimental condition, half featured an SOA of $-175 \mathrm{msec}$, and half featured a 0 -msec SOA.

Procedure. The procedure was identical to that in Experiment 2. The participants were instructed to maintain fixation until the color change occurred and then to move their eyes to the target of a unique color and decide whether it contained a $\mathrm{C}$ or a reversed $\mathrm{C}$. The participants completed one block of 252 trials.

\section{Results and Discussion}

Accuracy for determining the identity of the target was $96 \%$. Overall, approximately $9 \%$ of the trials were excluded from analysis, due to participants failing to maintain fixation or responding incorrectly to the target or technical problems.

Oculomotor behavior. Figure 6 depicts the proportion of trials on which the first saccade went to the target or the distractor for each trial type. The proportion of trials on which the first saccade went to the target was entered into a two-way repeated measures ANOVA with SOA $(-175$ or $0 \mathrm{msec})$ as one factor and transient type (onset or offset) as another. This analysis revealed a main effect of SOA $[F(1,23)=4.75, p<.05]$, a main effect of transient type $[F(1,23)=38.75, p<.001]$, and no reliable interaction $[F(1,23)=2.0, p=.17]$. In general, transients occurring prior to the target disrupted eye movements to a greater extent, and onsets had a greater ability to disrupt the eyes than did offsets. Planned comparisons between each onset condition and the control condition revealed that onsets occurring $175 \mathrm{msec}$ prior to the color change disrupted saccades to the target $[F(1,23)=21.77, p<.001]$ and that onsets occurring with a $0-\mathrm{msec}$ SOA disrupted saccades to the target $[F(1,23)=25.08, p<.001]$. Comparisons of each offset condition with the control condition revealed that offsets occurring $175 \mathrm{msec}$ before the target disrupted goal-directed eye movements $[F(1,23)=$ $6.88, p=.015]$ but offsets occurring simultaneously with the target did not $[F(1,23)=0.358, p=.555]$.
An identical ANOVA was performed on the proportion of eye movements that were captured by each transient type. This ANOVA revealed no effect of SOA $[F(1,23)=1.83$, $p=.67]$, a main effect of transient type $[F(1,23)=52.30$, $p<.001]$, and no reliable interaction $[F(1,23)=2.36$, $p=.14]$. When an onset occurred at the negative SOA, the eyes erroneously went to the location of the onset on $12 \%$ of the trials, and when an onset occurred simultaneously with the color change, the eyes went to the location of the onset on $13.4 \%$ of the trials. This is in contrast to the offset condition, in which the eyes went to the offset on $4.1 \%$ of the trials in the negative SOA condition and $1.4 \%$ in the 0 -msec SOA condition. Despite offsets at the negative SOA disrupting eye movements to the target, the eyes went to the onset three times as often in the negative SOA condition, suggesting that onsets dominate oculomotor capture both when the distractor occurs simultaneously with the color change and when the distractor occurs slightly before the color change.

Saccadic latencies. Table 2 lists saccadic latencies and RTs for each trial type. Saccadic latencies were analyzed using only those trials on which the eyes went directly to the target. A two-way repeated measures ANOVA with SOA as one factor and transient type as the other factor revealed no effect of SOA $[F(1,23)=1.61, p=.22]$, no effect of transient type $[F(1,23)=0.01, p=.93]$, and no significant interaction $[F(1,23)=0.01, p=.75]$. Latencies of eye movements that went to the onset were considerably shorter in the negative SOA condition than in the 0 -msec SOA condition [131.33 vs. $223.24 \mathrm{msec} ; t(19)=$ $-4.04, p<.01]$. Latencies were also shorter when the eyes went to the offset in the negative SOA condition, as compared with the $0-\mathrm{msec}$ SOA condition [141.95 vs. $246.73 \mathrm{msec} ; t(7)=-4.29, p<.01]$. One interesting issue that arises is why saccadic latencies of eye movements to the transient distractors are not $175 \mathrm{msec}$ shorter in the negative SOA condition than in the 0 -msec SOA condition. In the negative SOA condition, presumably, an eye movement to the transient distractor can be pro-

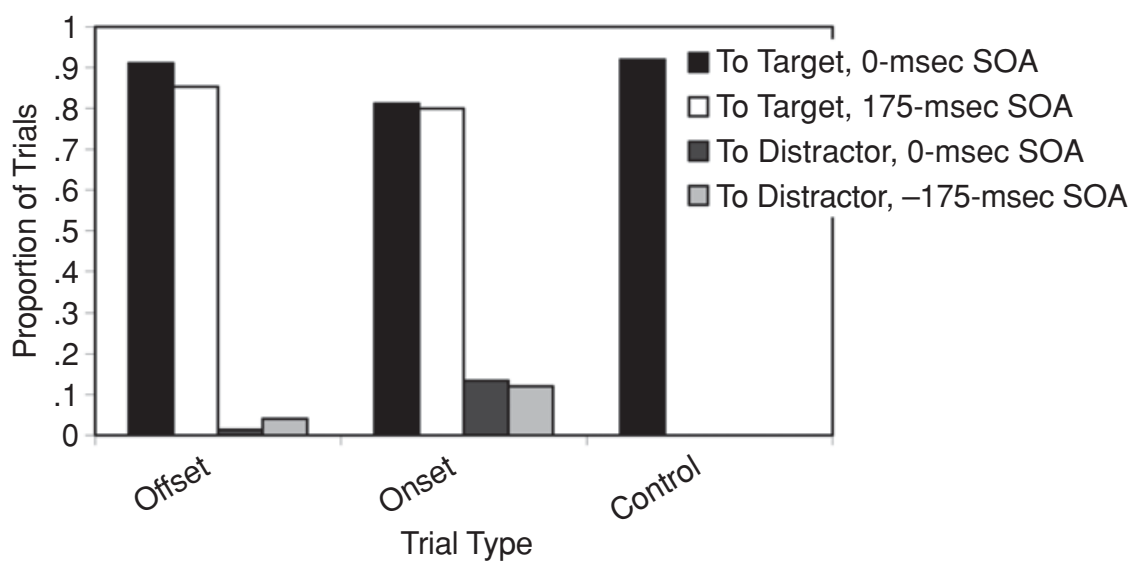

Figure 6. Mean proportion of trials on which the first saccade went to the target or the distractor for each condition in Experiment 4. 
Table 2

Mean Saccadic Latency and Reaction Time (in Milliseconds) for Each Condition in Experiment 4 as a Function of Stimulus Onset Asynchrony (SOA) Length for Trials on Which the Eyes Went Directly to the Target

\begin{tabular}{|c|c|c|c|c|c|}
\hline & \multicolumn{5}{|c|}{ Condition } \\
\hline & \multirow[b]{2}{*}{ Control } & \multicolumn{2}{|c|}{$-175-\mathrm{msec}$ SOA } & \multicolumn{2}{|c|}{0 -msec SOA } \\
\hline & & Offset & Onset & Offset & Onset \\
\hline $\mathrm{s}$ & 298 & 297 & 298 & 302 & 301 \\
\hline Reaction time & 879 & 887 & 882 & 884 & 882 \\
\hline
\end{tabular}

grammed as soon as the transient occurs. This may be due in part to the fixation offset effect's decreasing saccadic latency in the 0 -msec SOA condition. The fixation offset effect describes the shortening of saccadic latencies when a fixation point is removed before or simultaneously with the appearance of a saccade target (e.g., Kingstone \& Klein, 1993). In the negative SOA condition, the fixation point remains while participants are preparing and initiating an eye movement to the transient distractor. However, in the 0 -msec SOA condition, the fixation offsets simultaneously with the transient distractor, allowing a saccade to be initiated more quickly.

Saccadic latencies were also analyzed by comparing trials on which the eyes went to the target and those on which the eyes went to the distractor for each trial type. Saccadic latencies were significantly shorter when the eyes erroneously went to the location of the offset than when the eyes went to the target in the negative SOA offset condition [164.59 vs. $269.22 \mathrm{msec} ; t(13)=6.47, p<.001]$. The same was true of saccades that erroneously went to the onset, rather than to the target, in the negative SOA onset condition [126.67 vs. $297.54 \mathrm{msec} ; t(20)=7.75$, $p<.001]$. A comparison of the two negative SOA conditions revealed no significant difference in latency between when the eyes went to the onset and when the eyes went to the offset, although latencies tended to be shorter when the eyes went to the onset [131.58 vs. $166.72 \mathrm{msec} ; t(12)=$ $-1.89, p=.084]$. One possibility as to why onsets are more likely to capture the eyes is that onsets generate a faster exogenous signal, which gives onsets an advantage over offsets when competing with endogenous shifts of attention to the target. This trend for latencies to be shorter when the eyes go to the onset, as compared with the offset, lends some support to this speculation.

Another possibility is that on some of the trials in the negative SOA condition, the participants might have mistakenly, but not reflexively, moved their eyes to the first singleton they detected. This is similar to the attentional capture explanation offered by Bacon and Egeth (1994), in which participants sometimes adopt a singleton detection mode, rather than a feature detection mode. This would result in a mixture of reflexive and nonreflexive saccades when the eyes go to the distractor in the negative SOA condition. Evidence from the previous four experiments would suggest that onsets might generate a greater proportion of reflexive saccades, which might explain this trend for latencies to the onset to be shorter. When an offset occurred at the 0 -msec SOA, too few participants made eye movements to the offset to interpret any latency difference between eye movements that went to the target and those that went to the offset (only 10 out of 24 participants). However, the data from those participants indicated a trend for latencies to be slightly shorter when the eyes went to the offset at the 0-msec SOA than when the eyes went directly to the target [ 248.63 vs. $274.60 \mathrm{msec} ; t(9)=$ $2.31, p=.046) .{ }^{4} \mathrm{~A}$ significant latency difference existed between when the eyes went to the onset and when the eyes went to the target in the $0-\mathrm{msec}$ SOA condition [227.065 vs. $298.56 \mathrm{msec} ; t(16)=7.36, p<.001]$. A comparison of latencies for those trials on which the eyes went to the offset and those on which the eyes went to the onset in the 0 -msec SOA condition revealed significantly shorter latencies when the eyes went to the onset than when they went to the offset [212.77 vs. $254.26 \mathrm{msec} ; t(8)=-3.76$, $p<.01]$. What these data appear to suggest is that capture by offsets might be of the same reflexive nature as capture by onsets but that offsets might generate a slower exogenous signal, giving goal-directed shifts of attention to the color singleton an advantage.

Reaction time. RT for only those trials on which the first saccade went to the target were entered into an identical two-way repeated measures ANOVA, which revealed no effect of SOA $[F(1,23)=0.05, p=.83]$, no effect of transient type $[F(1,23)=0.24, p=.63]$, and no reliable interaction $[F(1,23)=0.07, p=.80]$. RTs were compared between those trials on which the eyes went to the target and those on which the eyes went to the distractor for each trial type. When the eyes went to the onset in the -175 -msec condition, RTs were significantly longer than when the eyes went directly to the target $[1,087.90$ vs. $870.70 \mathrm{msec} ; t(20)=-7.04, p<.001]$. The same was true of trials on which the first saccade went to the onset, as compared with the target, in the 0 -msec onset condition $[1,033.56$ vs. $887.64 \mathrm{msec} ; t(22)=-4.36, p<.01]$. However, no significant RT difference was found between when the eyes went to the offset and when the eyes went to the target when the offset occurred at the negative SOA [ 952.36 vs. $841.06 \mathrm{msec} ; t(13)=-1.62, p=.130]$ or the 0 -msec SOA [985.68 vs. $873.34 \mathrm{msec} ; t(10)=-2.121$, $p=.058]$. Although it is puzzling why no RT difference was found when the eyes erroneously went to the offset, interpretation of these results must be cautious, given that very few eye movements actually went to the location of the offset and a number of participants were excluded from analysis because they never made eye movements to the location of the offset (10 in the negative SOA offset condition, 13 in the 0 -msec SOA offset condition).

The results of Experiment 4 are mixed as to the ability of offsets to capture the eyes. Even if offsets do have some ability to capture the eyes, their ability to do so is rather limited (4.1\% in the negative SOA condition). The results of Experiment 4 do not strongly support the hypothesis that offsets can capture the eyes, even in the absence of simultaneous goal-directed shifts of attention to the target. 


\section{EXPERIMENT 5}

Experiments 1-4 tell a remarkably consistent story. The oculomotor system is especially concerned with the appearance of new objects. The disappearance of an object, however, has little or no effect on oculomotor control. This is quite interesting, given the body of work reviewed, using different paradigms, that suggests that both the appearance and the disappearance of an object capture covert attention (e.g., Chastain \& Cheal, 2001; Pratt \& McAuliffe, 2001; Samuel \& Weiner, 2001; Theeuwes, 1991; Watson $\&$ Humphreys, 1995). The results of the experiments reported thus far indicate that during oculomotor search, onsets, but not offsets, will disrupt eye movements. Experiments $5 \mathrm{~A}$ and $5 \mathrm{~B}$ were attempts to replicate previous findings that both onsets and offsets will disrupt covert attention during search.

\section{Experiment 5A}

To observe the effect of onsets and offsets on covert attention, participants completed a search task similar to the one employed in the previous experiments reported here, with the exception that search letters were made large enough that the participants could search without eye movements. In the first covert attention experiment, two manipulations were made in order to observe the interaction between goal-directed and stimulus-driven shifts of attention. First, the onset/offset transient could occur either simultaneously with or before $(-175 \mathrm{msec})$ the search display. Therefore, in the negative SOA condition, any exogenous shifts of attention to the transient did not have to compete with simultaneous shifts of attention to the target. Second, the target could be either a singleton (a uniquely colored item) or a nonsingleton in the display. A singleton target should provide stronger endogenous competition for any stimulus-driven shifts of attention, since it is clear where attention should be allocated in the display. A nonsingleton target should provide less competition, leading to more capture.

\section{Method}

Participants. Thirty participants (13 males and 17 females), ranging in age from 18 to 27 years, were paid $\$ 6$ for their participation. All the participants demonstrated normal color vision, as measured by the Ishihara Color Blindness Test, and normal visual acuity, as measured by Snellen charts. One participant's data were lost due to computer malfunction.

Apparatus. A 486-based computer with a 17 -in. color monitor was used to present all the stimuli. The participants' eye movements were not recorded, but the importance of maintaining fixation was stressed. Head position was not restrained, but the participants viewed displays from an average distance of $76 \mathrm{~cm}$.

Stimuli. The participants viewed displays containing six green figure eight premasks arranged around the perimeter of an imaginary circle with a radius of $4.75^{\circ}$ (see Figure 7). Two, three, or four gray circles (diameter of $2.3^{\circ}$ ) appeared around these premasks $\left(1.88^{\circ} \times 1.88^{\circ}\right)$. Circles and premasks could appear at positions of $1,3,5,7,9$, and 11 o'clock. A gray fixation cross measuring $0.15^{\circ}$ was located at the center of the screen. The participants completed one onset block of trials and one offset block of trials, with block order being counterbalanced across participants. In the onset block, the initial screen contained two or three gray circles around premask locations. After this initial display had been viewed for $1 \mathrm{sec}$, all of the premasks changed to letters. These letters were large enough to be identified from fixation. On half of the trials, the initial display contained two circles, and an additional gray circle was added to the display. This additional circle never appeared around the target location and could occur simultaneously with the letters' being revealed or $175 \mathrm{msec}$ before. The remaining trials were control trials on which three circles appeared in the initial display and no additional circle was added to the display. In the offset block, half of the trials contained the offset of a circle appearing around one of the premasks. On offset trials, the initial display contained four circles, and a gray circle was removed from the display. This offset location never coincided with the target location and could occur simultaneously with the letters' being revealed or $175 \mathrm{msec}$ before. In the offset control condition, three circles appeared in the initial display, and no circle was removed when the letters were revealed. On half of all the trials, the target appeared within a circle.

The target letter could be either a color singleton or a nonsingleton. Target type was manipulated between subjects. In the color singleton case, all of the premasks changed color to red $\left(1.0 \mathrm{~cd} / \mathrm{m}^{2}\right)$ when the letters were revealed, except for the target, which remained green $(2.0 \mathrm{~cd} /$ $\mathrm{m}^{2}$ ). In the nonsingleton case, all of the premasks changed color from green to red, including the target, when the letters were revealed.

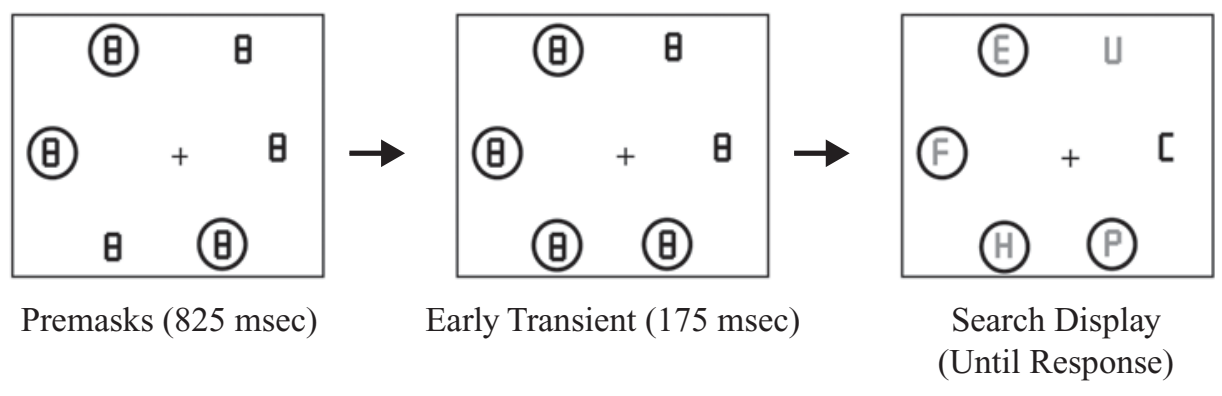

Figure 7. Example of the displays viewed in Experiment 5. Figure eight premasks were initially green (depicted as black), and all but one changed color to red (depicted as gray) when the search display was revealed in the singleton target condition. In the nonsingleton condition, all the premasks changed from green to red. Simultaneously with the color change or 175 msec prior to the color change, a circle could be added or deleted from the display. Depicted is a color singleton target trial with an onset occurring with a $-175-\mathrm{msec}$ SOA. 
Procedure. The participants were asked to search for a $\mathrm{C}$ or a reversed $\mathrm{C}$ in the search display and to indicate the identity of the target as quickly and as accurately as possible and were told that the transient distractor (onset or offset) did not predict the location of the target. The participants pressed the " $z$ " key if they detected a $\mathrm{C}$ and the " " key if they detected a reversed C. A tone indicated whether the participants had answered incorrectly. The participants were asked to find the target letter without moving their eyes from fixation. The participants completed one block of onset trials and one block of offset trials, with 216 trials in each block. On half of all the trials, a transient occurred (onset or offset); on half of all the transient trials, the transient occurred $175 \mathrm{msec}$ before the search letters were revealed, whereas on the other half, the transient occurred simultaneously with the search letters being revealed.

\section{Results and Discussion}

Accuracy for determining the identity of the character (C or reversed C) at the target location was high (approximately $96 \%$ in both the singleton and the nonsingleton target conditions). Since error rates were so low, they were not further analyzed.

Reaction time costs. An outlier removal process trimmed RTs greater or less than two standard deviations of the mean. Mean RTs for each condition are listed in Table 3. RT costs were computed for onset and offset distractors for each SOA by subtracting the mean RT in each experimental condition from that in the appropriate control condition. Costs are illustrated in Figure 8. A mixed model repeated measures ANOVA was performed on RT costs with SOA ( -175 vs. 0 msec) and transient type (onset vs. offset) as within-subjects factors and target type (singleton target vs. nonsingleton target) as a between-subjects factor. First and most important, this ANOVA revealed a main effect of transient type $[F(1,27)=4.29, p<.05]$ that did not interact with target type $[F(1,27)=0.737$, $p=.398]$ or SOA $[F(1,27)=0.589, p=.450]$. Overall, there was a greater RT cost for onsets with little or no cost for offsets, consistent with the oculomotor results of the previous experiments. This ANOVA also revealed a main effect of target type $[F(1,27)=6.10, p<.05]$, a marginal effect of SOA $[F(1,27)=3.93, p=.058]$, and a reliable interaction between SOA and target type $[F(1,27)=4.99$, $p<.05$ ]. Averaging across transient types (onset and offset), costs were greater when a transient occurred in the negative SOA condition than when one occurred in the 0 -msec SOA when the target was a nonsingleton [34-msec

Table 3

Mean Reaction Time (in Milliseconds) for Each Condition in Experiment 5A

\begin{tabular}{ccc}
\hline Condition & $-175-\mathrm{msec}$ SOA & 0 -msec SOA \\
\hline Singleton target & 637 & 637 \\
Onset & - & 625 \\
Onset control & 622 & 624 \\
Offset & - & 622 \\
Offset control & & \\
Nonsingleton target & 830 & 810 \\
Onset & - & 784 \\
Onset control & 766 & 755 \\
Offset & - & 750 \\
Offset control &
\end{tabular}

cost in the negative SOA condition vs. 20 -msec cost in the 0 -msec SOA condition; $t(13)=2.43, p<.05]$. However, average RT cost when a transient distractor occurred in the singleton target condition did not differ significantly between SOA conditions [6-msec cost in the negative SOA condition vs. 7 -msec cost in the 0 -msec SOA condition; $t(14)=0.237, p=.816]$. It is possible that a strong attentional set for a color singleton was able to prevent most capture in both the 0 - and the -175 -msec conditions when the target was a singleton. Without such a set, capture was greater, especially when the transient occurred early and in the absence of either color or target identity to guide attention to the correct location. The three-way interaction between SOA, target type, and transient type was also nonsignificant $[F(1,27)=0.556, p=.462]$.

The present data suggest the possibility that when the target was not a singleton, offsets in the negative SOA condition were able to induce slowing, although this difference was not significant and may have been due to a lack of power [16-msec difference; $t(13)=1.55, p=.15$ ]. These results are contrary to results in the literature that suggest that onset and offset transients have equal ability to capture covert attention (e.g., Theeuwes, 1991) but are consistent with other studies suggesting that onset transients may control attention more effectively (e.g., Miller, 1989). A number of potential explanations can account for why sometimes offset transients show strong attentional capture effects, whereas other times these effects may be weak or, in the case of the present experiment, virtually absent. These factors are further discussed in the General Discussion section. However, before concluding that offsets have little effect on covert attention, Experiment 5B was performed to once again attempt to replicate previous findings of covert attentional capture.

\section{Experiment 5B}

In Experiment 5B, we again attempted to replicate the finding that offsets capture covert attention. A number of important differences existed between this experiment and Experiment 5A. First, similar to our previous oculomotor experiments, onsets and offsets were mixed within one block, rather than presented in separate blocks. In addition, eye movements were recorded in this experiment, and all the trials on which the participants moved their eyes were discarded. This experiment focused on the 0 msec SOA condition.

\section{Method}

Participants. Twenty-four participants (11 males and 13 females), ranging in age from 18 to 33 years, were paid $\$ 8$ for their participation. All the participants demonstrated normal color vision, as measured by the Ishihara Color Blindness Test, and normal visual acuity, as measured by Snellen charts.

Apparatus. The same apparatus was used as that in Experiments $1-4$.

Stimuli. Displays were similar to those in the previous experiments. First, the participants viewed six red premasks $\left(1.3^{\circ} \times 1.3^{\circ}\right)$ arranged around the perimeter of an imaginary circle with a radius of $5.6^{\circ}$. Two, three, or four gray circles with a diameter of $2.6^{\circ}$ could appear around these premasks. After $1 \mathrm{sec}$, line segments were removed 


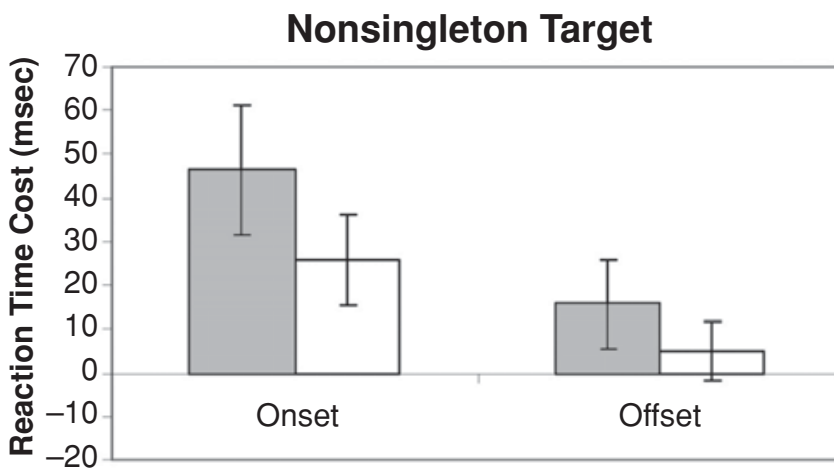

\section{$\square$ Negative SOA $\square 0$-msec SOA}

Transient Type

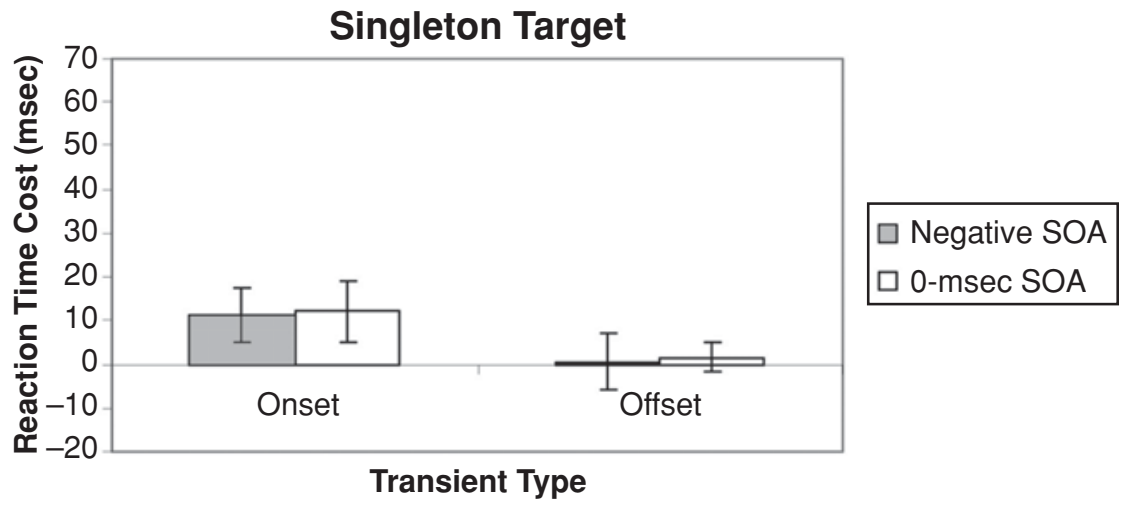

Figure 8. Mean reaction time cost for onsets and offsets in Experiment 5A. Error bars represent plus and minus one standard error.

to reveal letters including the target $(\mathrm{C}$ or reverse $\mathrm{C})$. In the singleton target condition, simultaneously with the removal of line segments to reveal the search letters, all the items changed color to green, except for the target. In the nonsingleton target condition, the items remained red. At the same time that the search letters were revealed, one circle could onset or offset from the display. In the singleton target condition, each participant matched the luminance of the green that the distractor items changed to with a red having a luminance of $8.75 \mathrm{~cd} / \mathrm{m}^{2}$. This same red was used in the nonsingleton target condition.

Procedure. Half of the participants completed the singleton target condition. The participants were asked to find the target and to indicate its identity as quickly and as accurately as possible without moving their eyes from the center of the screen. The participants completed 480 trials: 150 onset trials, 150 offset trials, and 180 control trials. For onset trials, initially, three circles were presented, and $1 \mathrm{sec}$ later, a fourth circle was added to the display. For offset trials, three circles appeared, and one of these circles was removed from the display. The onset or offset never occurred around the target location, and the target was equally likely to occur with or without a circle surrounding it. Out of the 180 control trials, 60 each contained two, three, or four circles in the display.

\section{Results and Discussion}

Accuracy for determining target identity was lower when the target was a nonsingleton than when it was a singleton ( $88 \%$ vs. $95 \%)$. This can be accounted for by the increased difficulty of a serial search. However, RTs indicate that speed was not traded for accuracy (Table 4). Approximately equal numbers of trials were discarded, due to eye movements, in the nonsingleton and the singleton target conditions ( $17 \%$ and $16 \%$, respectively).

Reaction time costs. For onset and offset conditions, RT costs were computed by subtracting the appropriate control condition from each transient condition (i.e., controls were matched to the distractor conditions on the basis of the number of objects in the final display; for onset, cost was calculated by subtracting RT in the four-circle control from that in the onset condition; for offset, cost was calculated by subtracting RT in the two-circle control from that in the offset condition). Costs are depicted in Figure 9. An ANOVA was conducted on these costs, with transient type (onset or offset) as a within-subjects factor and target type (singleton vs. nonsingleton) as a betweensubjects factor. This ANOVA revealed no effect of target type $[F(1,22)=0.39, p=.54]$, a significant effect of

Table 4

Mean Reaction Time (in Milliseconds) for Each Condition in Experiment 5B

\begin{tabular}{lcc}
\hline \multicolumn{1}{c}{ Condition } & Singleton Target & Nonsingleton Target \\
\hline Onset & 585 & 672 \\
Onset control (4 circles) & 560 & 639 \\
Offset & 559 & 640 \\
Offset control (2 circles) & 552 & 627 \\
Control (3 circles) & 550 & 630 \\
\hline
\end{tabular}




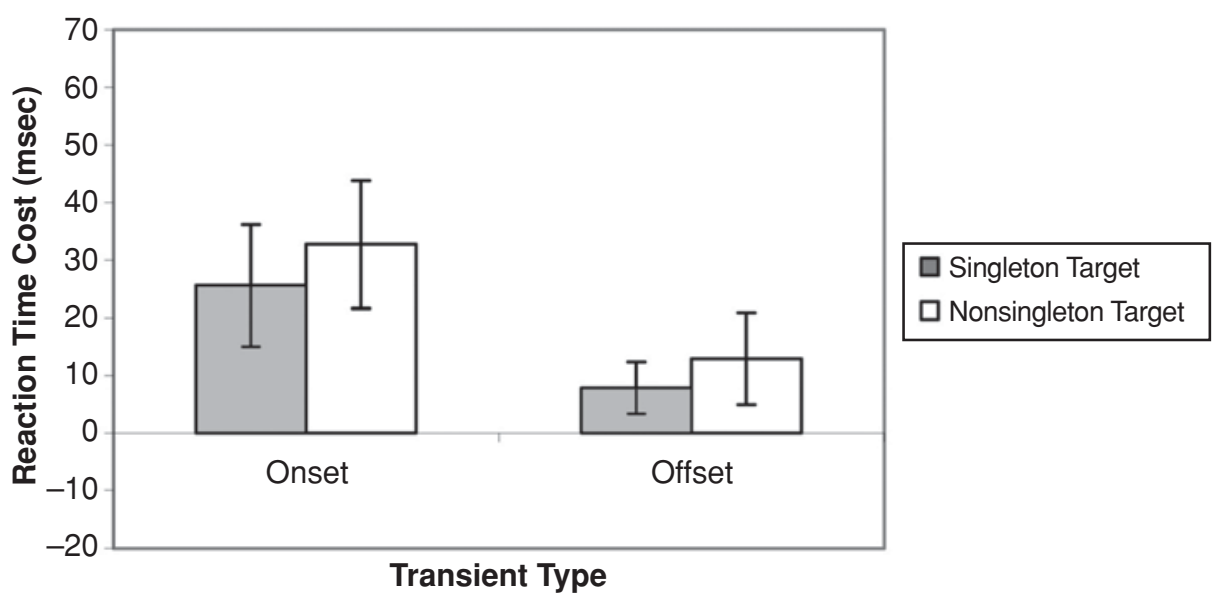

Figure 9. Mean reaction time cost for onsets and offsets in Experiment 5B. Error bars represent plus and minus one standard error.

transient type $[F(1,22)=6.51, p<.05]$, and no significant interaction between these factors $[F(1,22)=0.13$, $p=.73]$. On average, onsets produced a $30-\mathrm{msec}$ cost, whereas offsets produced approximately a 10 -msec cost. An investigation of just the offset costs combined across target conditions revealed a significant cost when an offset was present [598 vs. $589 \mathrm{msec} ; F(1,22)=5.17, p<.05]$. Overall, the results of Experiment 5B suggest that offsets do have attentional consequences, but to a lesser degree than do onsets. It should be noted that Experiment 5B did not replicate the results of Experiment 5A, in that capture was approximately equal whether the target was a singleton or not. Since these experiments varied in a number of different ways, it cannot be determined exactly why this was the case. However, the most critical finding was replicated. Although offsets did show the ability to slow search, onsets had a much greater ability to do so.

\section{GENERAL DISCUSSION}

It has been argued that attentional capture by onsets is mediated by the perception of a new object (Yantis \& Hillstrom, 1994; Yantis \& Jonides, 1996). For example, Yantis and Hillstrom proposed that the appearance of a new object in the visual environment necessitates the creation of an object file (see Kahneman, Treisman, \& Gibbs, 1992) and that this process causes attention to be drawn to the new object. This is consistent with studies showing little or no influence of irrelevant color or luminance singletons on the allocation of attention (Enns et al., 2001; Gibson \& Jiang, 1998; Jonides \& Yantis, 1988; Todd \& Kramer, 1994), since these changes might involve the updating, but not the creation, of an object file. There are obvious reasons why the onset of a new object in the visual environment might be given attentional priority. An abruptly appearing object might signify a change requiring immediate response (such as the appearance of a predator). Therefore, it is important that new objects be processed and identified quickly. However, this explanation does not account for studies showing that the offset of an object can also capture attention. It is more difficult to imagine a situation in which the sudden disappearance of an object from the visual environment might be as significant as the sudden appearance of an object. Yet a number of studies have shown that offsets can influence the allocation of attention (Atchley et al., 2000; Chastain \& Cheal, 2001; Martin-Emerson \& Kramer, 1997; Miller, 1989; Pratt \& McAuliffe, 2001; Samuel \& Weiner, 2001; Theeuwes, 1991). These studies have looked at the influence of offsets on covert attention. The results of the five experiments presented here suggest that offsets do not capture the eyes and have only a weak ability to capture covert attention (as compared with onsets). These findings generally support a new-object theory of attentional capture. Potential explanations for the weak covert findings observed here and the covert findings reported in previous experiments will be discussed further below.

Experiment 1 focused on the oculomotor consequences of complete onsets and offsets. A complete offset was not able to disrupt goal-directed eye movements to the color singleton target and was not able to cause an overt shift of attention to the location of the offset. In contrast, onsets were able to capture the eyes on a large percentage of trials. Onsets in Experiment 1 were also able to slow RT to the target identity, even when the eyes went directly to the target, but no RT difference was present for offsets. This might suggest that the onsets in Experiment 1 were able to influence not only overt attention, but also covert attention. In Experiment 2, a partial contour offset was used, and it was shown that even when there remained a location in the display for an eye movement to be programmed to and an object for attention to be directed toward, offsets still did not capture the eyes. Reversing the direction of the luminance change of onsets and offsets did little to affect capture by onsets and offsets (see Samuel \& Weiner, 2001, for a similar result). Onsets still captured the eyes when they led to a luminance decrement. The only manipulation that hinted at the ability of offsets to capture the 
eyes was when the offset occurred slightly before the color change revealing the location of the target. However, the amount of capture was small, as compared with capture by onsets.

An attempt to reconcile this apparent discrepancy between our overt attentional findings and the extant attentional literature indicated that covert attention was not strongly affected by an antipredictive offset. However, onsets demonstrated a robust capture effect. It could be that covert attention has a more liberal criterion for what is worthy of an attentional shift, with covert attention going to the offset even when the eyes do not. For example, eye movements might be more "costly" to program and execute, as compared with covert shifts of attention; therefore, a greater threshold might need to be reached to produce an eye movement, as compared with a covert shift. However, this does not appear to be the case. Experiment 5 suggests that the eyes do not go to the location of the offset, because the offsets have limited ability to capture covert attention. Therefore, a discrepancy exists between the covert and the overt attentional findings in Experiments 1-5 and those in previous research on offset capture.

One factor that might be relevant to this discrepancy is distractor validity and how attentional capture is measured when a singleton is irrelevant, as compared with when it is antipredictive. In many studies in which the effect of offsets on attention have been examined, the distractor cooccurs with the target location with some probabilityusually, chance (e.g., Atchley et al., 2000; Chastain \& Cheal, 2001; Samuel \& Weiner, 2001; Theeuwes, 1991). Attending first to the offset distractor neither helps nor hinders performance, since the target is as likely to occur at the distractor position as it is to occur at any other location. The offsets in the series of experiments presented here were truly task irrelevant, in the sense that they never co-occurred at the target position and attending to the distractor would always result in poorer performance. This is a stronger definition of capture. In addition, when singletons are not antipredictive of target location, capture is usually measured by combining both cuing effects when the singleton is the target and costs when it is not. Onsets might create larger costs, while cuing effects of onsets and offsets might be equal. This could be explained by the additional cost of processing a new object when attention is drawn to an onset, whereas there is no new object to process when an offset occurs. There is evidence of this being the case in the data presented by Theeuwes. In his graphs of RT cuing and costs for the 200-msec SOA condition (when attention is not focused in advance), both onsets and offsets demonstrate cuing effects, but costs when an offset appears at a distractor location are minimal. This lends support to the quick disengagement hypothesis (Samuel \& Weiner, 2001).

It should be noted that in many attentional capture studies, the onset/offset has little competition for attention. For example, in the Theeuwes (1991) study, only the target's identity could guide attention. Target and distractor stimuli were very similar (stimuli were formed by removing some line segments from figure eight premasks, ensuring high target/distractor similarity). In our paradigm, the onset/ offset must also compete with strong endogenous shifts of attention to a salient color singleton target. The percentage of eye movements to the offset was largest when the offset occurred slightly before the color change revealing the target location, suggesting that in the absence of strong competition, offsets might have some ability to attract the eyes. Onsets still were able to capture the eyes on more trials in the absence of strong competition, suggesting that onsets have a special role in controlling overt attention.

Another possibility is that the offset capture observed in some experiments may be the result of contingent capture (Folk \& Remington, 1998; Folk et al., 1992; Folk et al., 1994). Folk and colleagues have shown, in numerous studies, that top-down expectancies, rather than bottom-up stimulusproperties, can explain why certain features capture attention. Atchley et al. (2000) clearly demonstrated that this is one possibility in the case of offsets. When participants had an attentional set for either onsets or offsets, only distractors consistent with their attentional set captured attention. When no attentional set for onsets or offsets could be formed, both changes captured attention, suggesting that the participants formed an attentional set that included both types of distractors. This is one possibility that would explain why Chastain and Cheal (2001) found that both onsets and offsets captured attention even when no screenwide attentional set could be adopted. An attentional set for transients could have been adopted, which would explain why they found capture for onsets, offsets, and morphs (shape change of an existing object). It could be that a default attentional set for change is adopted when no other attentional set is active. However, it is highly unlikely that such a default attentional set was active in our experiments, given that the target was always a unique color singleton. If the participants had been relying on an attentional set, an attentional set for color would have made search most efficient, since the color singleton always indicated the target location.

Returning to the study of Theeuwes (1991) as an example, it is possible that properties of the search display itself might bias participants to attend to offsets. Gibson and Kelsey (1998) showed that capture depended critically on the method through which the search display was revealed. If the search display onset (all items appearing at once), onset cues, but not color cues, captured attention. If the search display onset with all letters presented in a particular color, both onset cues and color cues matching the color of the search items captured attention. Note that even though all the items in the display had onset and color properties (including the target), these properties provided no information about the location of the target (although they may have provided a temporal cue as to when to begin search). Gibson and Kelsey argued that claims of stimulus-driven attention capture need to address issues of displaywide attention set. The displays of Theeuwes did not meet the more stringent criteria for capture as defined by Gibson and Kelsey. It is likely that the manner of stimulus presentation induced a displaywide attention set for offsets. Search items were revealed by offsetting line 
segments from premasks. These offsetting line segments were of the same color and luminance as the offset cues used. Given the findings of displaywide attention sets, it is probable that the capture observed in some offset studies may have been induced by properties of the task and were not stimulus driven. Atchley et al. (2000), using displays very similar to those in Theeuwes, found that offsets captured attention when the target display was presented through the removal of line segments from premasks, but not when the display onset, confirming that offsets might capture only when the task creates an attentional set for offset transients.

One additional possibility is that the offsets used in our series of experiments may not have been ideal. Many studies focusing on the effects of offsets on the allocation of attention have used what may better be classified as morphs (see Samuel \& Weiner, 2001, for a discussion of the difference between true offsets and morphs). Morph offsets involve an already existing object changing shape or identity through the offset of part of the object (e.g., Chastain \& Cheal, 2001; Martin-Emerson \& Kramer, 1997; Miller; 1989; Watson \& Humphreys, 1995). Although the main intention in our partial offset experiments was to give the eyes a target to be directed to after an object had offset, it can still be said that the object that we hoped would induce capture completely disappeared from the display. That is, if the attention shifts in this task are driven in an object-based manner, the complete offset of an object that was partially occluding another object might not be as effective as the morph of one object into another. It may be possible that morph offsets have the ability to capture the eyes, given that complete offsets and morph offsets are likely to have different attentional consequences. Further research is needed to investigate this possibility.

Recent work by $\mathrm{Wu}$ and Remington (2003) illustrates several interesting dissociations between attention and oculomotor capture. For example, when participants were induced into a feature search mode, rather than a singleton search mode (see Bacon \& Egeth, 1994), the participants demonstrated no attentional capture by onsets, yet still showed a significant amount of oculomotor capture. This work questions previous assumptions of relatively tightly linked attentional and oculomotor control systems. However, the data presented here do not suggest such a dissociation when it comes to offsets. In our covert attention experiments, the power of offsets to capture attention (under these specific conditions) can be described as weak at best. These covert attentional findings are consistent with our overt attentional findings. Onsets, on the other hand, captured both covert and overt attention.

Oculomotor behavior in the experiments presented is consistent with a horse race model of saccade generation in which both an endogenous and an exogenous saccade are programmed in parallel (Irwin et al., 2000; Kramer et al., 2001; Kramer et al., 2000; Peterson et al., 2004; Theeuwes et al., 1998; Theeuwes et al., 1999). The first program that is finished is then executed. Exogenous saccades to an onset appear to be reflexive in nature, as evi- denced by their shorter latencies, as compared with when the eyes go to the target location. The same appears to be true of those few eye movements going to the offset. Parallel programming of saccades is also suggested by the extremely brief fixations on the distractor location (onset or offset) before the eyes go to the target. These fixations are generally too short for the programming of a new saccade, and it is assumed that the saccade to the color singleton target is programmed before the eyes land on the distractor. Given the similarity between saccades that go to the onset and saccades that go to the offset, it appears that both may be of the same nature, with onsets having a much greater ability to capture the eyes. This may be due to onsets having the ability to generate a faster exogenous signal, allowing onsets to win control of attention more often than do offsets when competing with simultaneous endogenous shifts of attention to the target. However, even when offsets were given a 175 -msec advantage over the programming of goal-directed saccades, onsets still captured the eyes on a much greater proportion of trials. This would suggest that there may be a qualitative, rather than a quantitative, difference between the exogenous signals created by onsets and offsets.

In summary, the consensus of the results reported here is that onsets receive attentional priority over offsets when the onset/offset is never associated with the target location. When each type of distractor must compete with simultaneous or delayed goal-directed shifts of attention, onsets win control of attention much more often than do offsets. Eye movements toward an irrelevant offset are rarely made, and little evidence was found for antipredictive offsets being able to strongly influence covert attention. These results are consistent with the idea that onsets might receive attentional priority, since the quick processing of new objects in the environment is highly adaptive.

\section{REFERENCES}

Atchley, P., Kramer, A. F., \& Hillstrom, A. P. (2000). Contingent capture for onsets and offsets: Attentional set for perceptual transients. Journal of Experimental Psychology: Human Perception \& Performance, 26, 594-606.

BACON, W. F., \& EGETH, H. E. (1994). Overriding stimulus-driven attentional capture. Perception \& Psychophysics, 55, 485-496.

Chastain, G., \& Cheal, M. (2001). Attentional capture with various distractor and target types. Perception \& Psychophysics, 63, 979990.

Deubel, H., \& Schneider, W. X. (1996). Saccade target selection and object recognition: Evidence for a common attentional mechanism. Vision Research, 36, 1827-1837.

Enns, J. T., Austen, E. L., Di Lollo, V., Rauschenberger, R., \& YANTIS, S. (2001). New objects dominate luminance transients in setting attentional priority. Journal of Experimental Psychology: Human Perception \& Performance, 27, 1287-1302.

Folk, C. L., \& Remington, R. [W.] (1998). Selectivity in distraction by irrelevant featural singletons: Evidence for two forms of attentional capture. Journal of Experimental Psychology: Human Perception \& Performance, 24, 847-858.

Folk, C. L., Remington, R. W., \& Johnston, J. C. (1992). Involuntary covert orienting is contingent on attention control settings. Journal of Experimental Psychology: Human Perception \& Performance, 18, 1030-1044.

Folk, C. L., Remington, R. W., \& Wright, J. H. (1994). The structure 
of attentional control: Contingent capture by apparent motion, abrupt onset, and color. Journal of Experimental Psychology: Human Perception \& Performance, 20, 317-329.

Gibson, B. S., \& JiAnG, Y. (1998). Surprise! An unexpected color singleton does not capture attention in visual search. Psychological Science, 9, 176-182.

Gibson, B. S., \& Kelsey, E. M. (1998). Stimulus-driven attentional capture is contingent on attentional set for displaywide visual features. Journal of Experimental Psychology: Human Perception \& Performance, 24, 699-706.

Godisn, R., \& Theeuwes, J. (2002). Oculomotor capture and inhibition of return: Evidence for an oculomotor suppression account of IOR. Psychological Research, 66, 234-246.

Irwin, D. E., Colcombe, A. M., Kramer, A. F., \& Hahn, S. (2000). Attentional and oculomotor capture by onset, luminance and color singletons. Vision Research, 40, 1443-1458.

Jonides, J., \& YANTIS, S. (1988). Uniqueness of abrupt visual onset in capturing attention. Perception \& Psychophysics, 43, 346-354.

Kahneman, D., Treisman, A., \& Gibbs, B. J. (1992). The reviewing of object files: Object-specific integration of information. Cognitive Psychology, 24, 175-219.

Kingstone, A., \& Klein, R. M. (1993). Visual offsets facilitate saccadic latency: Does predisengagement of visuospatial attention mediate this gap effect? Journal of Experimental Psychology: Human Perception \& Performance, 19, 1251-1265.

KLEIN, R. M. (2000). Inhibition of return. Trends in Cognitive Sciences, 4, 138-147.

KLEIN, R. M., \& SHORE, D. I. (2000). Relations among modes of visual orienting. In S. Monsell \& J. Driver (Eds.), Attention and performance XVIII (pp. 195-208). Cambridge, MA: MIT Press, Bradford Books.

Kowler, E., Anderson, E., Dosher, B., \& Blaser, E. (1995). The role of attention in the programming of saccades. Vision Research, 35, 1897-1916.

Kramer, A. F., Cassavaugh, N. D., Irwin, D. E., Peterson, M. S., \& HAHN, S. (2001). Influence of single and multiple onset distractors on visual search for singleton targets. Perception \& Psychophysics, 63, 952-968.

Kramer, A. F., Hahn, S., Irwin, D. E., \& Theeuwes, J. (2000). Age differences in the control of looking behavior: Do you know where your eyes have been? Psychological Science, 11, 210-217.

Martin-Emerson, R., \& Kramer, A. F. (1997). Offset transients modulate attentional capture by sudden onsets. Perception \& Psychophysics, 59, 739-751.

McPeeK, R. M., Skavenski, A. A., \& Nakayama, K. (2000). Concurrent processing of saccades in visual search. Vision Research, 40, 2499-2516.

MiLleR, J. (1989). The control of attention by abrupt visual onsets and offsets. Perception \& Psychophysics, 45, 567-571.

Müller, H. J., \& RabbitT, P. M. A. (1989). Reflexive and voluntary orienting of visual attention: Time course of activation and resistance to interruption. Journal of Experimental Psychology: Human Perception \& Performance, 15, 315-330.

Nikolic, M. I., OrR, J. M., \& SARTer, N. B. (2004). Why pilots miss the green box: How display context undermines attention capture. International Journal of Aviation Psychology, 14, 39-52.

Peterson, M. S., Kramer, A. F., \& Irwin, D. E. (2004). Covert shifts of attention precede involuntary eye movements. Perception \& Psychophysics, 66, 398-405.

Pratt, J., \& Hirshhorn, M. (2003). Examining the time course of facilitation and inhibition with simultaneous onset and offset cues. Psychological Research, 67, 261-265.

Pratt, J., \& McAuliffe, J. (2001). The effects of onsets and offsets on visual attention. Psychological Research, 65, 185-191.

RAUSCHENBERGER, R., \& YANTIS, S. (2001). Masking unveils pre-amodal completion representation in visual search. Nature, 410, 369-372.

Remington, R. W., Johnston, J. C., \& Yantis, S. (1992). Involuntary attentional capture by abrupt onsets. Perception \& Psychophysics, 51, 279-290.
Samuel, A. G., \& Weiner, S. K. (2001). Attentional consequences of object appearance and disappearance. Journal of Experimental Psychology: Human Perception \& Performance, 27, 1433-1451.

TheEuwes, J. (1991). Exogenous and endogenous control of attention: The effect of visual onsets and offsets. Perception \& Psychophysics, 49, 83-90.

Theeuwes, J., \& Godisn, R. (2001). Attentional and oculomotor capture. In C. L. Folk \& B. S. Gibson (Eds.), Attraction, distraction and action: Multiple perspectives on attentional capture (pp. 121-149). New York: Elsevier.

Theeuwes, J., Kramer, A. F., Hahn, S., \& Irwin, D. E. (1998). Our eyes do not always go where we want them to go: Capture of the eyes by new objects. Psychological Science, 9, 379-385.

Theeuwes, J., Kramer, A. F., Hahn, S., Irwin, D. E., \& Zelinsky, G. J. (1999). Influence of attentional capture on oculomotor control. Journal of Experimental Psychology: Human Perception \& Performance, 25, 1595-1608.

Todd, S., \& Kramer, A. F. (1994). Attentional misguidance in visual search. Perception \& Psychophysics, 56, 198-210.

Watson, D. G., \& Humphreys, G. W. (1995). Attention capture by contour onsets and offsets: No special role for onsets. Perception \& Psychophysics, 57, 583-597.

Wu, S., \& Remington, R. W. (2003). Characteristics of covert and overt visual orienting: Evidence from attentional and oculomotor capture. Journal of Experimental Psychology: Human Perception \& Performance, 29, 1050-1067.

Yantis, S., \& Hillstrom, A. P. (1994). Stimulus-driven attentional capture: Evidence from equiluminant visual objects. Journal of Experimental Psychology: Human Perception \& Performance, 20, 95-107.

Yantis, S., \& Jonides, J. (1984). Abrupt visual onsets and selective attention: Evidence from visual search. Journal of Experimental Psychology: Human Perception \& Performance, 10, 601-621.

Yantis, S., \& Jonides, J. (1990). Abrupt visual onsets and selective attention: Voluntary versus automatic allocation. Journal of Experimental Psychology: Human Perception \& Performance, 16, 121-134.

YANTIS, S., \& JonidES, J. (1996). Attentional capture by abrupt onsets: New perceptual objects or visual masking? Journal of Experimental Psychology: Human Perception \& Performance, 22, 1505-1513.

\section{NOTES}

1. It should be noted that the partial offsets we chose to use differed from the partial offsets used in previous work. For example, Watson and Humphreys (1995) and Martin-Emerson and Kramer (1997) studied offsets in which parts of an object disappeared (line segments were removed from complex premasks or letters). Our offsets consisted of an entire object's disappearing from a potential target location. We refer to these as partial offsets, since another salient object remains at this location after the disappearance of the offset object.

2. A $t$ test on the percentage of trials on which the eyes erroneously went to the onset revealed no significant difference in oculomotor capture between onsets in Experiments 1 and 2 [ $t(12)=1.67, p=.109]$. A two-way (distractor type $\times$ experiment) mixed ANOVA on the percentage of trials on which the eyes first went toward the distractor (onset or offset) revealed a main effect of distractor type $[F(2,44)=33.79, p<$ $.001]$, no effect of experiment $[F(1,22)=0.651, p=.428]$, and no reliable interaction $[F(2,44)=3.16, p=.079]$.

3 . The degrees of freedom equaled 10 for this paired $t$ test and for the other comparisons between trials based on the direction of the first saccade in Experiment 2, because 1 participant showed no oculomotor capture and never made a first saccade to the onset object.

4. One participant was excluded from this analysis and other analyses of saccadic latencies in the 0 -msec offset condition, since the only saccade made to the offset had a latency that was abnormally long $(760 \mathrm{msec})$.

(Manuscript received August 29, 2003; revision accepted for publication October 24, 2004.) 